\title{
Adolescent Girls Initiative-Kenya: Baseline report
}

Karen Austrian

Population Council

Eunice N. Muthengi

Population Council

Taylor Riley

Joyce Mumah

Caroline W. Kabiru

See next page for additional authors

Follow this and additional works at: https://knowledgecommons.popcouncil.org/departments_sbsr-pgy

Part of the Demography, Population, and Ecology Commons, Family, Life Course, and Society Commons, Gender and Sexuality Commons, and the International Public Health Commons How does access to this work benefit you? Let us know!

\section{Recommended Citation}

Austrian, Karen, Eunice N. Muthengi, Taylor Riley, Joyce Mumah, Caroline W. Kabiru, and Benta Abuya. 2015. "Adolescent Girls Initiative-Kenya: Baseline report." Nairobi: Population Council. 
Authors

Karen Austrian, Eunice N. Muthengi, Taylor Riley, Joyce Mumah, Caroline W. Kabiru, and Benta Abuya

This report is available at Knowledge Commons: https://knowledgecommons.popcouncil.org/departments_sbsr-pgy/ 
0 AGI-K

Adolescent Girls Initiative-Kenya BASELINE REPORT

SEPTEMBER 2015
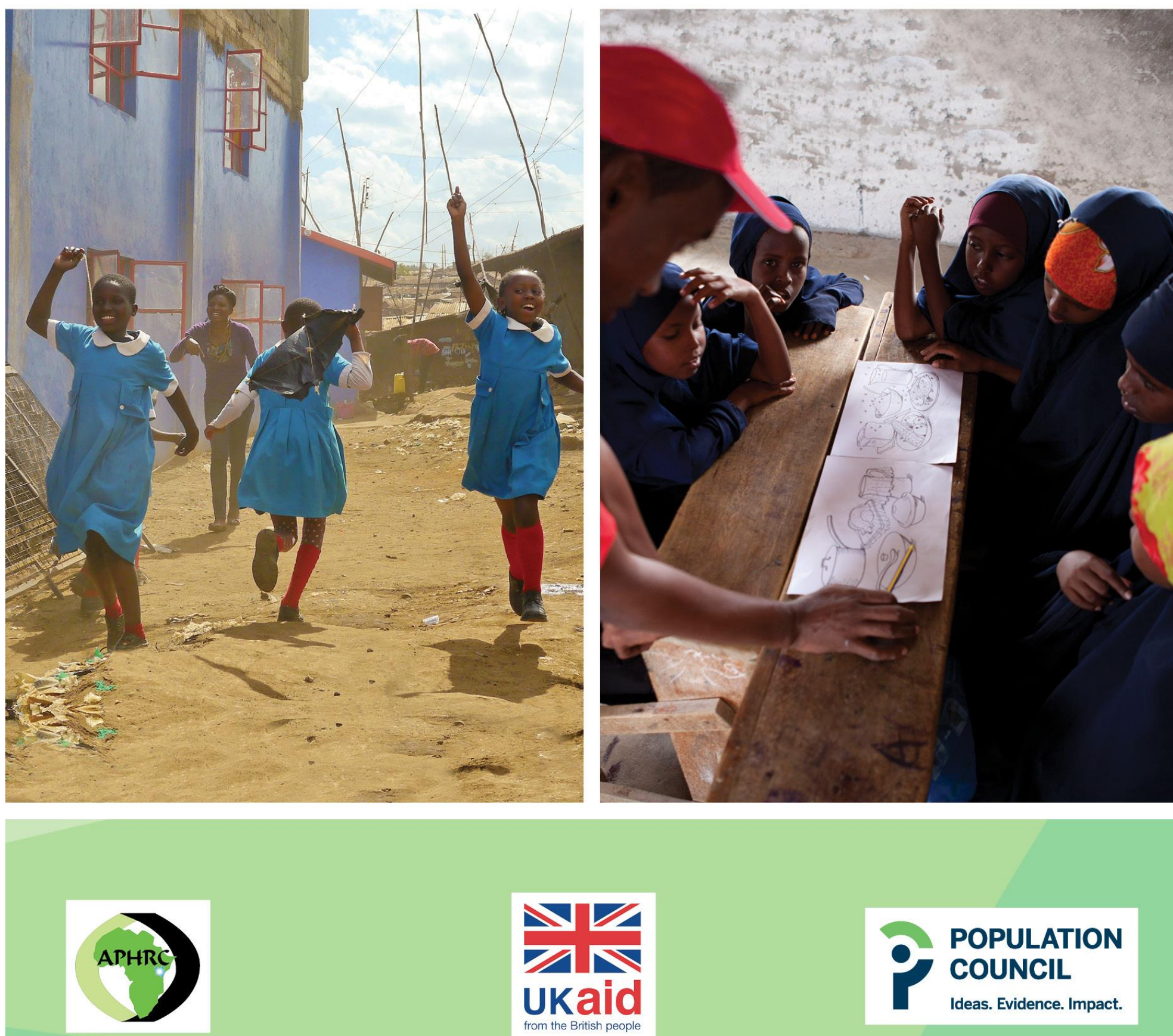


\section{POPULATION}

COUNCIL

Ideas. Evidence. Impact.

The Population Council confronts critical health and development issues-from stopping the spread of HIV to improving reproductive health and ensuring that young people lead full and productive lives. Through biomedical, social science, and public health research in 50 countries, we work with our partners to deliver solutions that lead to more effective policies, programs, and technologies that improve lives around the world. Established in 1952 and headquartered in New York, the Council is a nongovernmental, nonprofit organization governed by an international board of trustees.

Population Council

General Accident House

Ralph Bunche Road

PO Box 17643-00500

Nairobi

Kenya

Tel: +254202713480

Tel2: +254202713481

Fax: +254202713479

www.popcouncil.org

\section{AUTHORS}

\section{CONTRIBUTING AUTHORS}

\section{Karen Austrian, PhD}

AGI-K Team Leader

Associate

Population Council, Kenya

kaustrian@popcouncil.org

Eunice Muthengi, PhD

AGI-K Deputy Team Leader

Associate

Population Council, Kenya

Taylor Riley

MPH Candidate, Columbia

University

Graduate Intern

Population Council, Kenya
Joyce Mumah, PhD

Associate Research Scientist APHRC

Caroline W. Kabiru, PhD

Research Scientist APHRC

Benta A. Abuya, PhD

Research Scientist

APHRC
Erica Soler-Hampejsek, PhD

Associate

Population Council,

New York

John Maluccio, PhD

Associate Professor of

Economics

Middlebury College

Suggested citation: Austrian, K., Muthengi, E., Riley, T., Mumah, J., Kabiru, C., and Abuya, B. 2015. “Adolescent Girls Initiative-Kenya Baseline Report." Nairobi: Population Council.

Photos: (I) Sam Lowenberg; (r) Save the Children 


\section{Table of Contents}

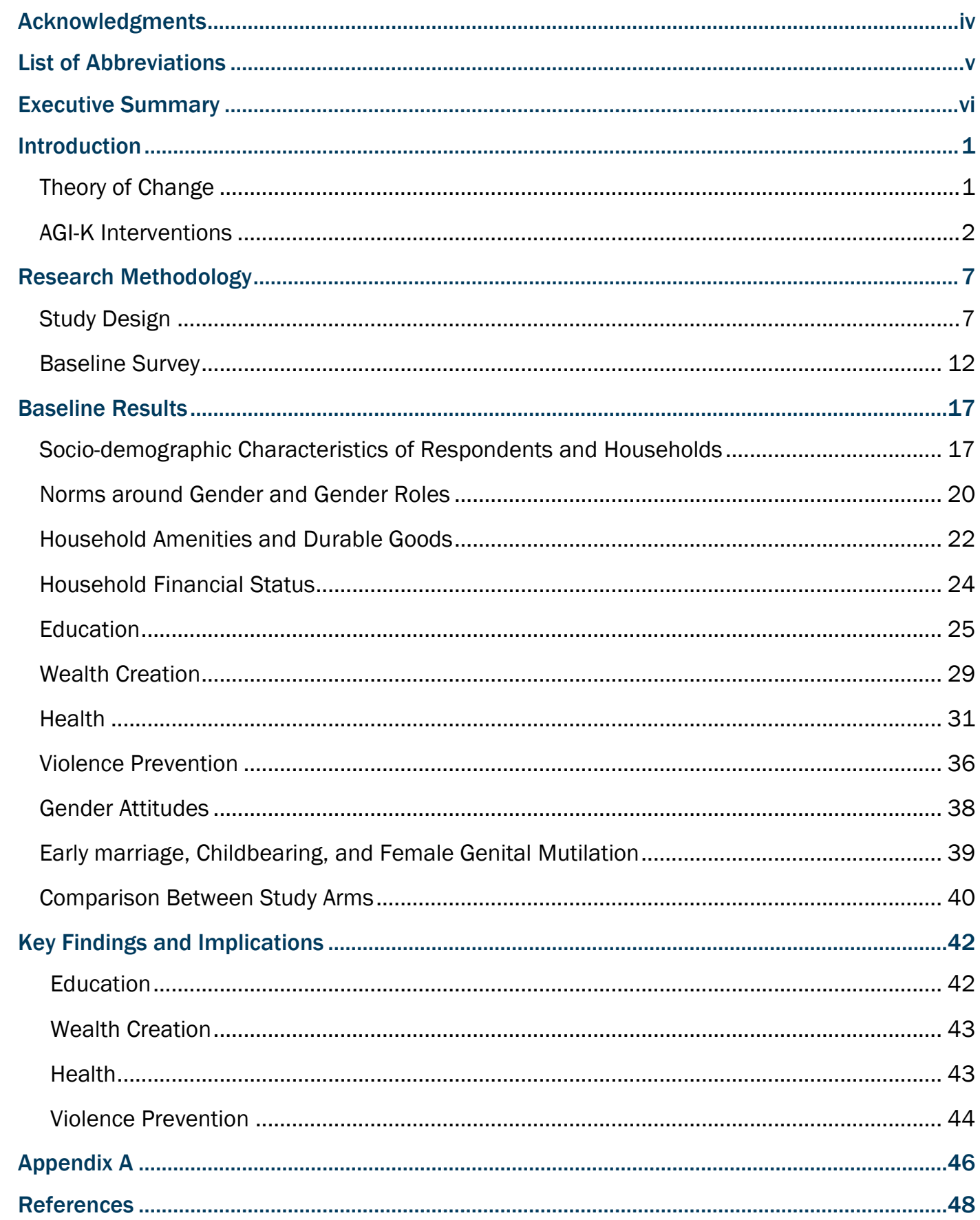




\section{Acknowledgments}

The AGI-K baseline report would not be possible without the hard work of the project partners and research teams dedicated to improving the lives of vulnerable adolescent girls. AGI-K is implemented by a consortium led by the Population Council, with the African Population and Health Research Centre (APHRC) as research partner, Save the Children as implementing partner in Wajir, Plan International as implementing partner in Nairobi slums, and Itad as consultant on the cost-effectiveness analysis. We would like to thank all of the project members as well as the members of the AGI-K National External Advisory Committee (EAC) as well as the Kibera and Wajir EACs for their invaluable input into the intervention and research design (see Appendix A).

We would like to acknowledge the efforts of the large team of dedicated research assistants and supervisors who collected the data, led by Phanuel Owiti in Kibera and James Serembe in Wajir. The entire exercise was coordinated by AGI-K Study Coordinator Eva Muluve, with logistical support by Philisters Obunga, both based in the Population Council office in Kenya. We thank Paul Macharia for programming the tools using Open Data Kit for electronic data capture. We also thank Population Council's AGI-K Program Coordinator, Diana Moreka, and Program Managers Joyce Kimani of Save the Children and Joy Koech of Plan International, for overall management and oversight of intervention activities.

The authors thank the UK Department for International Development (DFID) for investing in rigorous research that will provide evidence to influence national policy and will support scaledup, cost-effective interventions for adolescent girls in the future. We also thank those from DFID-Kenya and the AGI-K Expert Research Committee who provided feedback on the research design and on drafts of this report.

Finally, we are grateful to the adolescent girls and their parents/guardians who participated in the research and took the time to share their thoughts and experiences with us. 


\section{List of Abbreviations}

AGI-K Adolescent Girls Initiative-Kenya

APHRC African Population and Health Research Center

CAPI Computer-Assisted Personal Interviewing

CCT Conditional Cash Transfer

DFID Department for International Development

EAC External Advisory Committee

ERC Expert Research Committee

FE Financial Education

FGM/C Female Genital Mutilation/Cutting

HSNP Hunger Safety Net Program

KDHS Kenya Demographic and Health Survey

KES Kenya Shillings

KNBS Kenya National Bureau of Statistics

ODK Open Data Kit

RCT Randomized Controlled Trial

SES Socioeconomic Status

STI Sexually Transmitted Infection

UCT Unconditional Cash Transfer 


\section{Executive Summary}

Many adolescent girls in Kenya face considerable risks and vulnerabilities that affect their education status, health, and general well-being. The Adolescent Girls Initiative-Kenya (AGI-K) will deliver multi-sectoral interventions for over 5,000 girls ages 11-14 in two marginalized areas of Kenya: 1) Kibera slums in Nairobi and 2) Wajir County in Northeastern Kenya. Implemented by Plan International in Kibera and Save the Children in Wajir, these interventions will be implemented for two years and will comprise a combination of girl-level, household-level, and community-level interventions. A randomized controlled trial (RCT) will be used to compare the impact of four different packages of interventions, together with their costs, in order to assess if and how intervening in early adolescence will impact girls' life chances. This report describes the intervention and research design of AGI-K as well as the findings from the baseline survey.

\section{KEY FINDINGS}

Baseline results from Kibera and Wajir suggest that although young adolescents face a myriad of challenges, the majority have not experienced risks associated with poor sexual and reproductive health outcomes. Intervening in the different sectors (education, wealth, health, and violence prevention) therefore has the potential to delay or prevent negative outcomes as adolescents make the transition to adulthood in resource-constrained settings.

Overall, there were stark differences between Kibera (urban slum) and Wajir (rural area) in all four sectors. The differences between Nairobi and Wajir justify the importance of looking at these as separate substudies. 


\section{Education}

One in four girls in Wajir had never attended school compared to less than $1 \%$ of girls in Kibera. Similarly, about a quarter of the girls in Wajir were in the expected class relative to their age, compared to $71 \%$ of girls in Kibera. However, in Kibera, older girls were more likely to be behind in their schooling, indicating that progression through grades might also be poor. The AGI-K education intervention, a cash transfer conditioned on attendance, seeks to increase enrollment in Wajir and improve grade progression and transition to secondary school in both Kibera and Wajir.

\section{Wealth Creation}

Overall, girls had low levels of financial literacy and savings. Although over $40 \%$ of girls in Kibera had access to cash, which they spent on their daily needs in the previous year, fewer than $30 \%$ had any savings. In Wajir, less than $1 \%$ of girls reported having savings. The low levels observed in the baseline results suggest a critical need for the AGI-K wealth-creation interventions, which will build girls' economic well-being by equipping them with moneymanagement skills and teaching them to save at a young age.

\section{Health}

Low levels of sexual activity were found among study participants, with only $2 \%$ of girls in both Kibera and Wajir having already initiated sex. (All sexually active girls in Wajir were married.) These low levels of sexual initiation at baseline mean that more girls stand to benefit from the interventions to delay sexual initiation and the timing of first birth. The baseline results also highlighted limited menstrual knowledge among adolescents in both settings, but especially in Wajir. Overall, results highlight the need to strengthen sexual and reproductive health education for very young adolescents and to equip them with culturally relevant, accurate, and ageappropriate information. The AGI-K health intervention will deliver this information using the Safe Spaces model, which has been shown to have a positive impact on young people, including increased sexual and reproductive health knowledge in both rural and urban settings.

\section{Violence Prevention}

About a third of girls in Kibera reported that they had experienced emotional, physical, and sexual violence. In contrast, fewer than $5 \%$ of girls in Wajir reported that they had experienced any of these forms of violence. Nonetheless, almost one-third of girls in Wajir reported that they felt scared of being raped and over 1 in 10 said a boy or man had touched them indecently in the past six months. Overall, there was general acceptance of female genital mutilation/cutting (FGM/C) in Wajir, as the practice is widespread and common in the region. 
Equal proportions of young girls in both Kibera and Wajir agreed that a husband is justified in beating a wife for at least one reason, however a higher proportion of girls in Wajir agreed with reasons such as "going out without telling him," "refusing to have sexual intercourse with him," and "burning food." Results suggest ingrained gender norms around the status of women in the communities, which may be influencing girls' attitudes as well as their perceived low status relative to their male counterparts. The AGI-K violence-prevention intervention, community conversations focused on improving the value of girls within the community, will seek to improve the enabling environment for girls.

In conclusion, though the results from the baseline study highlight a number of negative issues affecting young girls in Kibera and Wajir, results also show potential promise in investing in young adolescent girls. By building girls' assets through a combination of education, social, health, and economic interventions, there is potential to change their life course. The data generated from AGI-K will help us understand the kinds of interventions that are best positioned to help us achieve this goal. 


\section{Introduction}

Many adolescent girls in Kenya face considerable risks and vulnerabilities that affect their education status, health, and general well-being. In addition to low educational attainment and health risks - including early marriage, teenage pregnancy, early and unprotected sexual activity, nonconsensual sex, and HIV/STIS - other factors that impact education and health outcomes include household poverty, lack of economic independence, limited income-earning opportunities, illiteracy, violence, and social isolation. Younger adolescent girls who live in environments laden with these vulnerabilities are at risk of experiencing negative outcomes such as school dropout, early sexual initiation, unintended pregnancy, early marriage, and sexual and gender-based violence. Therefore, it is critical to intervene before the myriad of challenges girls face result in outcomes that are irreversible or are costly to compensate for or reverse.

The root causes of these vulnerabilities work in tandem to create the current situation for adolescent girls - cultural norms that do not empower women and girls, acceptance of violence, poverty, social isolation, economic vulnerability, lack of voice in society - and therefore the interventions that will enable girls ages 11-14 to make a safe and healthy transition through adolescence and into adulthood must be integrated as well. In order to achieve well-being for girls in early and late adolescence, no single-sector intervention - whether it be education, health, wealth creation, or prevention of violence - will be adequate.

The Adolescent Girls Initiative-Kenya (AGI-K) will deliver multi-sectoral interventions for over 5,000 girls ages 11-14 in two marginalized areas of Kenya ( 2,500 in each): 1) Kibera slums in Nairobi and 2) Wajir County in Northeastern Kenya. Implemented by Save the Children in the North and Plan International in Nairobi, these interventions will be implemented for two years and will comprise a combination of girl-level, household-level, and community-level interventions. A randomized controlled trial (RCT) will be used to compare the impact of four different packages of interventions, together with their costs, to assess if and how intervening in early adolescence will impact girls' life chances.

This report describes both the intervention and research design of AGI-K, and presents the findings from the baseline data collection. These findings paint a picture of the life of very young adolescents living in rural areas of Wajir County and urban slums of Nairobi.

\section{THEORY OF CHANGE}

The interventions for AGI-K were based on the Asset Building Theory of Change that posits that girls need a combination of education, social, health, and economic assets to make a safe, healthy, and productive transition from childhood into young adulthood.1, 2 In addition, community norms regarding girls' values must be strengthened to facilitate the increase in assets for girls and the resulting improvements in medium- and longer-term outcomes (see Figure 1). 


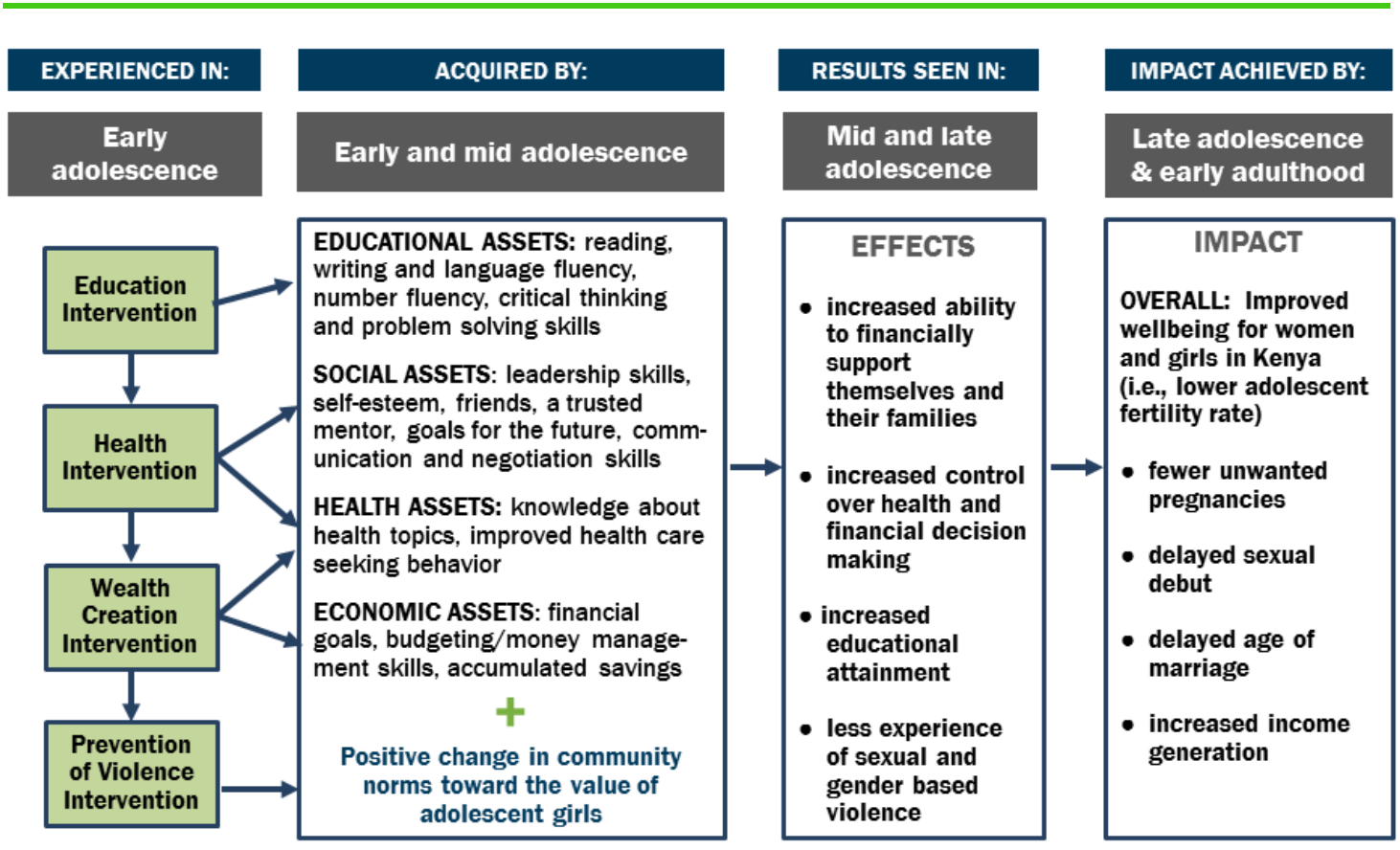

\section{AGI-K INTERVENTIONS}

As described above, the goal of AGI-K is not to test single-sector interventions but to test multisectoral packages of interventions. AGI-K will test the following packages:
1) Violence Prevention
2) Violence Prevention + Education
3) Violence Prevention + Education + Health
4) Violence Prevention + Education + Health + Wealth Creation

The selection of package combinations was based on three factors: 1) prioritizing what component effects were important to isolate; 2) generating evidence on new interventions and new combinations of interventions for which there are none; and 3) testing packages with varying implementation costs.

\section{Sector-Specific Interventions}

\section{Violence Prevention}

The violence-prevention intervention is a community-level intervention that uses the community dialogues and contracts strategy. While not much rigorous evaluation of this strategy has been published yet, the general consensus is that this is a promising intervention. We will be contributing to the literature on this approach when combined with other interventions. The strategy is to engage community members in dialogue to identify problems, develop their own solutions, and gain a sense of ownership in addressing social issues. It is important to involve 
key stakeholders that are often gatekeepers to girls' well-being. In addition, the definition of violence within the community is not limited to sexual and physical violence, but is a broader conceptualization of violence as the de-valuation of girls, including early marriage, lack of education, and FGM/C. Once a core committee is established in each village, they are taken through a facilitated process where they learn to identify the key issues in the community that lead to the under-valuing of girls, develop a "contract" of steps to address those issues, and then carry out activities to implement the contract over the course of the intervention period. A small amount of funds is available to implement the contract in each community. The committee is comprised of religious leaders, community leaders, parents, teachers, and young men and women.

\section{Education}

The education intervention is a conditional cash transfer (CCT) based on $80 \%$ attendance over the course of a term. All girls are eligible for the interventions irrespective of baseline schooling status (in or out of school). A household girl is eligible for the CCT for the entire two-year period and will receive the payment in any term where at least one girl in the household meets the attendance condition. There are four components to the transfer:

1. Fees: if applicable, paid at the start of each term, directly to the school, up to $1200 \mathrm{KES}$ per term for primary school and 6000 KES per term for secondary school. The initial payments, as well as payment of fees during the first term of each year, are conditional upon enrollment. The payment of second and third term fees are conditional upon attaining $80 \%$ attendance in the prior term.

2. Cash Transfer to Head of Household: Paid twice per term, the first payment based on attendance during the first month of the term and the second payment based on $80 \%$ attendance during the second and third months of the term (paid after the third month). The initial payments, as well as the first payment of each school year, are conditioned on enrollment and not attendance. The transfer in Nairobi is $1125 \mathrm{KES}$ per payment, for a total of 2250 KES per term. The transfer in Wajir is 1500 KES per payment, for a total of 3000 KES per term. The transfer amount reflects $9 \%$ of monthly household consumption in Wajir and $10 \%$ for urban slums in Nairobi. These amounts were determined based on needs assessments in the study communities, average household consumption in each site, and comparison to other education CCT amounts.

3. Kits: At the start of each term, a girl receives a schooling kit with the following items: 4 packs of sanitary towels, 2 panties, 1 small container of petroleum jelly, 1 bar of soap, 1 exercise book, and 1 pen. The provision of the kit follows the same conditioning rules as the school fees.

4. School Incentive: In addition to the fees, each school receives a top-up of $500 \mathrm{KES} /$ per girl enrolled in the CCT program. This is paid together with the fee payments at the start of the term. 
FIGURE 2 AGI-K education cash transfer payment schedule

\begin{tabular}{|c|c|c|c|c|c|c|c|c|c|c|c|c|c|c|c|c|c|c|c|c|c|c|c|c|c|}
\hline & \multicolumn{6}{|c|}{2015} & \multicolumn{12}{|c|}{2016} & \multicolumn{7}{|c|}{2017} \\
\hline & \multicolumn{2}{|c|}{ Term 2} & \multicolumn{4}{|c|}{ Term 3} & \multicolumn{4}{|c|}{ Term 1} & \multicolumn{4}{|c|}{ Term 2} & \multicolumn{4}{|c|}{ Term 3} & \multicolumn{4}{|c|}{ Term 1} & \multicolumn{3}{|c|}{ Term 2} \\
\hline & \begin{tabular}{|ll} 
Jul \\
\end{tabular} & Aug & Sep & Oct & Nov & Dec & Jan & Feb & Mar & Apr & May & Jun & Jul & Aug & Sep & Oct & Nov & Dec & Jan & Feb & Mar & Apr & May & Jun & Jul \\
\hline \multicolumn{26}{|l|}{ Fees } \\
\hline Cash Transfer & & & & $+n$ & & 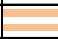 & & & & 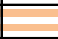 & & 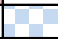 & & 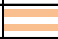 & & +2 & & 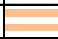 & & & & 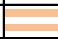 & & 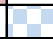 & \\
\hline \multicolumn{26}{|l|}{ Kit } \\
\hline \multicolumn{26}{|l|}{ School Incentive } \\
\hline & & & & & & & & & & & & & & & & & & & & & & & & & \\
\hline & & \multicolumn{5}{|c|}{ Conditioned on enrollment } & & & & & & & & & & & & & & & & & & & \\
\hline & & \multicolumn{8}{|c|}{ Conditioned on $80 \%$ attendance prior term } & & & & & & & & & & & & & & & & \\
\hline & 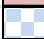 & \multicolumn{9}{|c|}{ Conditioned on $80 \%$ attendance in Month 1 of term } & & & & & & & & & & & & & & & \\
\hline & 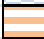 & \multicolumn{10}{|c|}{ Conditioned on $80 \%$ attendance in Months $2 \& 3$ of term } & & & & & & & & & & & & & & \\
\hline
\end{tabular}

Between June and August 2015, eligible households registered for the cash transfer program, providing details about the girl, school, and payments. At the time of registration, par-

ents/guardians participated in a sensitization session about the importance and value of girls' education. The Population Council has conducted a school quality survey that collected basic indicators on each school - including but not limited to teacher-student ratio, public versus private, number of female teachers, and the presence/type of latrines. These quality measures were not used to select schools for participation, however they will be accounted for in the analysis as a moderating factor in the relationship between the intervention and schooling outcomes.

School attendance is collected using two mechanisms. The first mechanism is biometric fingerprint reading at the start and end of each school day. The second mechanism is the review of attendance register records for the overall school. Mentors and other program staff will review the register records monthly. The two sources of attendance data will then be reconciled.

Results from a needs assessment conducted by Save the Children in Wajir showed that the key reasons that girls did not attend school were: 1 ) an overwhelming burden of domestic responsibilities, 2) lack of value for educating girls on the part of parents, and 3) early marriage. In the urban slum setting, Plan International found that school-related expenses and early pregnancy were the top barriers to girls' education. The CCT as described here is meant to address these issues by reducing the cost burden to the family for a girl's participation in school and incentivizing attendance with a monetary benefit to the household. The kits are given as a direct incentive for girls themselves and also to address issues of missed school due to lack of sanitary towels. The top-ups to the schools are given to address increased demand for education and the school's ability to cater to additional girls enrolled because of the program, as well as an incentive for them to help us with tracking attendance. The top-up is based on girls enrolled, and not conditioned on attendance, to reduce the risk of schools misreporting attendance data so as to receive the incentive.

Studies show that cash transfers conditioned on school attendance have been successful in increasing school attendance in sub-Saharan Africa. 3,4 Emerging evidence from the Save the Children run education CCT in Garissa County also showed that CCTs significantly increased enrollment by 4 percentage points and attendance by 3 percentage points, compared to the control group, while Unconditional Cash Transfers (UCTs) had no effect on enrollment or at- 
tendance. ${ }^{5}$ A systematic review of global CCT programs concluded that CCTs are a successful intervention for improving educational attendance, and are more effective than UCTs when tightly monitored. ${ }^{6}$ After reviewing additional education literature, it was concluded that CCTs have the most rigorous evidence and the most potential to directly address the main barriers to education (as compared with teacher report cards, sanitary towels alone, girls' toilet facilities, etc.).

Health

The health intervention will follow the Council's Safe Spaces model in which girls meet in groups once a week under the guidance of a female mentor from the community. ${ }^{1}$ Groups will be segmented by age (11-12 v. 13-14) in Nairobi and by schooling status in Wajir. The groups will follow a structured curriculum and will allow time for open discussion. The curriculum will include topics on hygiene, nutrition, HIV/AIDS, sexual and reproductive health, communication/negotiation skills, gender norms, sexual and gender-based violence, female genital mutilation/cutting (FGM/C), early marriage, leadership skills, and relationships. ${ }^{a}$ The curriculum will be adapted from existing modules that have been used by the Council in similar interventions, for each geographical setting (Wajir/Nairobi slums) to ensure that the context is culturally appropriate and acceptable by the community. In addition, certain sessions will be marked for the 13-14-year-olds only, if it is determined that these topics are appropriate only for the older cohort. The information from the needs assessment, as well as previous partner experience working in these sites, will guide the decisions on which sessions are acceptable.

Groups will meet in spaces identified in the community as safe and appropriate for girls, which could be community halls, schools, churches, mosques, community leaders' residences, and others. The groups will meet over the course of two years. This program length is in line with similar programs using the Safe Spaces model, because while one purpose is to deliver content, the other is to help girls build social assets such as friendships and adult mentor relationships.

There is growing literature showing that the Safe Spaces model has been successful in several countries in sub-Saharan Africa. 7,8 The mentor approach is used, as opposed to a peereducation approach where the group would be led by another girl of the same age, because the peer-education approach has not been shown to have a successful, positive impact on the beneficiaries (perhaps only on the peer educators themselves). ${ }^{9,} 10$

a One aim of the FGM sessions is to change girls' attitudes toward the practice to affect continuance of the practice with their own daughters. As it is likely that close to $100 \%$ of the girls in the study population will have already undergone FGM by age 11, the aim is not to change the prevalence of FGM among this population. 


\section{Wealth Creation}

The wealth-creation intervention is composed of savings and financial education, added on to the Safe Spaces groups. A financial education (FE) curriculum is added to the group sessions for the girls in the wealth-creation arm. These sessions help girls develop basic moneymanagement skills such as saving, budgeting, and differentiating between needs and wants.

In Wajir, girls in the wealth-creation arm also receive a home bank (piggy bank) with 300 KES in cash deposited inside after completing the first unit of five to six financial-education sessions. The purpose of the cash is to allow girls to immediately put into effect the skills learned through the financial education sessions. The results of two recent literature reviews evaluating financial education suggest that financial education is most effective in achieving sustained behavior change when the lessons learned can be put into practice at the time of the education. ${ }^{11,12}$ Therefore, the design includes an immediate opportunity for girls to start acting on their savings goals and budgets. An additional $300 \mathrm{KES}$ will be distributed at the start of the second year of the intervention for the same purpose.

In Kibera, girls in the wealth-creation arm are aided in opening Smata accounts with the Kenya Post Office Savings Bank (Postbank). These accounts differ from other "junior accounts" in the market in that they are opened and managed by the girls themselves. Girls need a co-signatory to open the account and make withdrawals. The co-signatory is a trusted adult above the age of 18 and selected by the girl. The program caters to the 200 KES minimum operating balance. A 300 KES deposit is made at account opening and at the start of the second year, following the reasoning explained above.

Evidence from two recent studies indicates that savings and financial education are effective methods of economic strengthening for adolescent girls - especially considering the young age of the girls and the approach of building direct assets for the girls themselves, as opposed to strengthening the household economic status and looking for a trickle-down effect to the girls. ${ }^{13,} 14$ 


\section{Research Methodology}

\section{STUDY DESIGN}

\section{Randomized Controlled Trial Design}

The research design was developed during a nine-month inception phase, incorporating findings from needs assessments, discussions, and workshops with study investigators, consultations with the External Advisory Committee ${ }^{b}$ and feedback from the Expert Research Committee $^{c}$ and the UK Department for International Development (DFID). The overall, Iong-term goal of the interventions is to reduce adolescent fertility by improving the well-being of girls in program sites. AGI-K will test multi-sectoral packages of interventions to answer the following research questions:

a) Which combination(s) of interventions produce(s) the greatest change in the well-being of adolescent girls?

b) What is the most cost-effective way to achieve the greatest impact for adolescent girls?

Due to the difference in context, cultures, cost-structures, and baseline characteristics on key indicators in Wajir and Nairobi, this study consists of two sub-studies with independent datasets: the Wajir sub-study and the Urban Nairobi Slums sub-study. While the intervention packages are the same across the two sub-studies, the actual interventions were modified to be culturally appropriate for each study area. Findings from both studies can be compared and conclusions can be made about whether the same packages of interventions had an impact on the same types of outcomes in both areas, or why there were major differences. Findings from Wajir could be cautiously generalized to other similar areas in Kenya, including semi-arid areas of Northeastern Kenya with similar populations, and findings from Nairobi could be cautiously generalized to other urban slums in Kenya having similar populations. Findings that are similar across both of these two very different areas can be expected to have implications for vulnerable girls in other areas of Kenya.

The research design for the study is a randomized controlled trial (RCT). The unit of randomization is different for the two sites: cluster randomization in Wajir and individual-level randomization in Nairobi. In Wajir, which is less densely populated, a cluster-level design allows for randomization to different combinations of interventions at the community level, while reaching a similar number of girls. In Nairobi, an individual-level RCT design results in increased statistical power with the same number of girls, and it is logistically possible to reach a large number of girls with excludable interventions within an urban setting. In addition, a nonexperimental external control site was included in the design for the Nairobi sub-study to enable comparison of

b The External Advisory Committee is a Population Council-convened group that advises on the general project strategy and promotes research uptake.

c The Expert Research Committee is a DFID-convened group that provides quality assurance/guidance for the project. 
intervention arms with a similar area that did not receive any of the four program interventions. Inclusion of an external control allows the research to identify impacts that can be attributed to each intervention package as a whole, identify the additional effect of adding another component, and examine the impact of the violence prevention-only arm by comparing it with a comparison site using quasi-experimental methodologies. In Wajir, it was not possible to have such an external control site, as community leaders indicated it was not socially acceptable to conduct research without providing some type of direct benefit. Therefore, it will not be possible to assess the impact of the violence-prevention intervention in Wajir.

The study protocol was approved by the Population Council Institutional Review Board and the AMREF Ethical and Scientific Review Committee. In addition, the protocol was reviewed by the Kenyan National Council for Science and Technology to obtain research permits for study investigators.

The project will be evaluated using data from behavioral surveys conducted at baseline, midterm, and endline; a cost-effectiveness and value-for-money costing study; a qualitative study to provide insights into the results shown in the quantitative data regarding the impact of the interventions; and program-monitoring data to track program attendance and participation.

For each sub-study, selected clusters/individuals will be randomly assigned to one of the four arms:
1) Violence Prevention Only
2) Violence Prevention + Education
3) Violence Prevention + Education + Health
4) Violence Prevention + Education + Health + Wealth Creation

FIGURE 3 Randomized controlled trial design

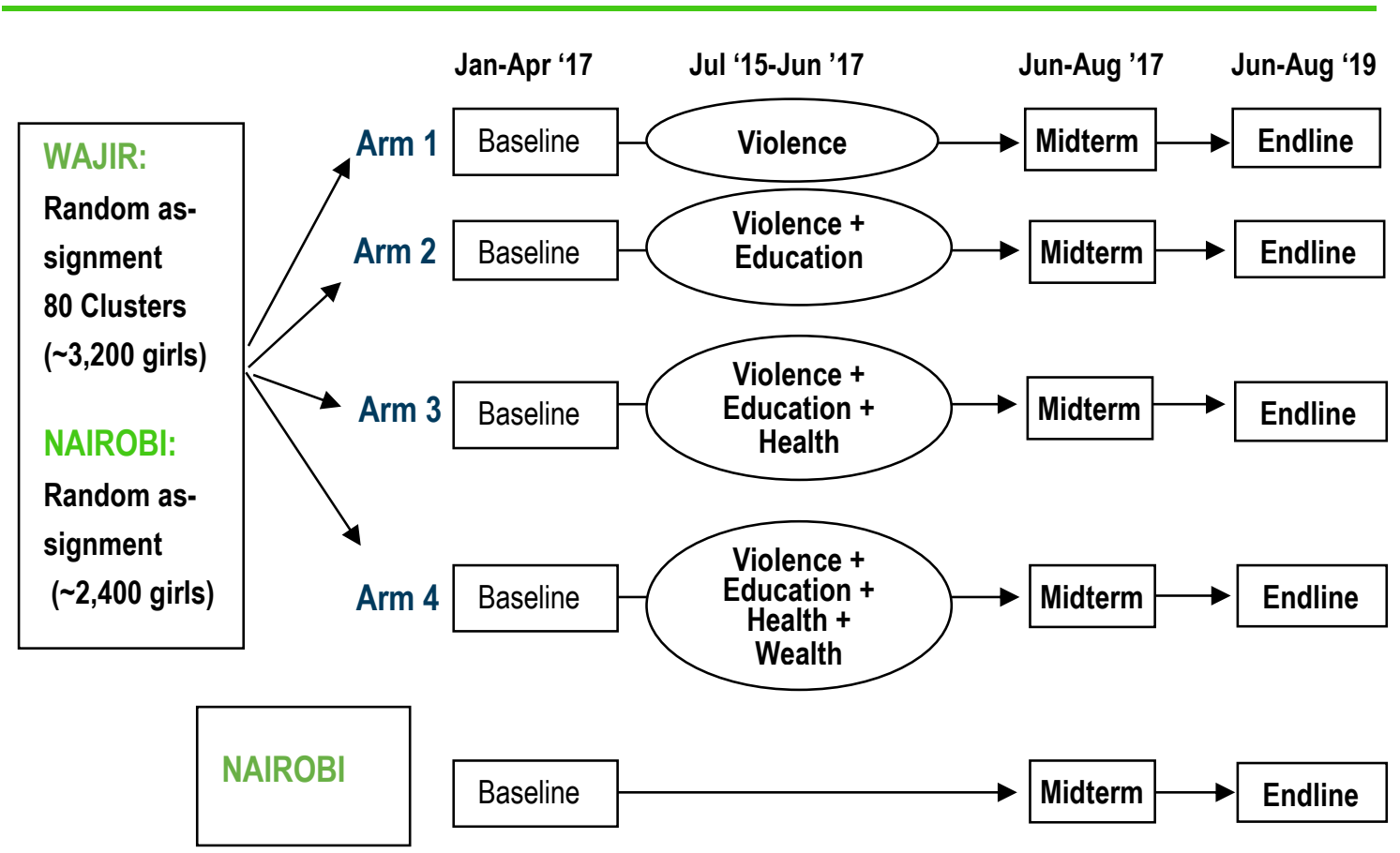




\section{Research Sites}

The research takes place in two areas: urban informal settlements (slums) in Nairobi and Wajir County in Northeastern Kenya. In both Nairobi and Wajir, the research is confined to selected geographical areas based on the target sample sizes. Since Kenya National Bureau of Statistics (KNBS) census population data were used to estimate sample sizes, administrative units are defined as per the pre-devolution ${ }^{d}$ units of Districts, Divisions, Locations, and SubLocations.

In Nairobi, eligible sites were identified using population data from the 2009 census for Nairobi County, as provided by the KNBS. Urban slum areas were defined as: (1) all sub-locations with enumeration areas designated as informal settlements by KNBS, and (2) all sub-locations with a population density greater than 20,000 people per square kilometer. The first definition was found to be inaccurate, because of the change in the structure of settlements in Nairobi since the time when KNBS conducted a mapping of residential areas. The second definition was added to include other densely populated areas that have since been developed. Based on this list, the selected sub-locations were categorized using KNBS designations of Locations, which are then categorized into Divisions. Areas where large adolescent girls programs are being implemented by the Population Council or APHRC (Viwandani, Korogocho, and Kariobangi), or the DFID Girls Education Challenge (Embakasi) were excluded.

Table 1 shows the seven divisions that were identified and the estimated number of girls aged 10 to $14^{\mathrm{e}}$ residing in selected sub-locations within those divisions. These estimates are based on data from the 2009 census and were obtained prior to the AGI-K household listing conducted in 2014. Of these, two districts (Kasarani and Pumwani) were ineligible because they include high socioeconomic-status areas of Nairobi. Three additional areas (Dagoretti, Makadara and Westlands) were ineligible because they did not have a sufficient number of adolescent girls to reach the target after accounting for nonresponse and refusals. Therefore, Kibera was identified as the primary research site. In Kibera Division, the selected locations classified as Urban Slums were: Kibera, Lindi, Makina, Silanga, Laini Saba, Soweto/Highrise, Gatwikira, and Olympic. Within those Kibera locations, the following areas were excluded due to their improved status as formal settlements: Fort Jesus, Karanja Cemetery, and Karanja PCEA in Makina; Ayany and Olympic sub-locations in Olympic; and Zone A and Nyayo Highrise in Soweto/Highrise. Central division (Huruma sub-location in Huruma location and Mlango Kubwa sublocation in Mathare location) was selected as the external control site due to similarity with Kibera on key characteristics based on secondary data. ${ }^{15}$

\footnotetext{
d In 2013, Kenya began a process of decentralization (devolution), where the 8 provinces and their administrators were replaced by 47 counties led by governors and county commissioners, and districts were reorganized as sub-counties headed by deputy commissioners.

e Note: Data for 10-14-year-old girls were obtained from KNBS before the decision to omit 10-year old girls from the study. This decision was made during the inception phase because most 10-year old girls were not expected to have experienced the primary outcomes of interest by the end of the study.
} 
TABLE 1 Estimated number of girls aged 10-14 residing in selected urban slums in Nairobi County based on 2009 census data and reason for selection or nonselection

\begin{tabular}{lcl}
\hline SELECTED DIVISIONS & $(\mathrm{N})$ & REASON FOR SELECTION/NONSELECTION \\
\hline $\begin{array}{l}\text { NAIROBI WEST DISTRICT } \\
\begin{array}{l}\text { Dagoretti Division } \\
\text { Kibera Division (selected areas) }\end{array}\end{array}$ & 3132 & $\begin{array}{l}\text { Excluded due to large presence of Girls Education Challenge } \\
\text { Selected as program site }\end{array}$ \\
$\begin{array}{l}\text { NAIROBI EAST DISTRICT } \\
\text { Makadara Division }\end{array}$ & 1186 & Excluded because it has less than 2000 girls \\
$\begin{array}{l}\text { NAIROBI NORTH DISTRICT } \\
\begin{array}{l}\text { Central Division } \\
\text { Kasarani Division }\end{array}\end{array}$ & 4059 & $\begin{array}{l}\text { Selected as external control site } \\
\text { Pumwani Division }\end{array}$ \\
$\begin{array}{l}\text { Higher socioeconomic status } \\
\text { WESTLANDS DISTRICT }\end{array}$ & 2119 & Higher socioeconomic status \\
Westlands Division & 3086 & Excluded because it has less than 2000 girls \\
\hline
\end{tabular}

In Wajir, clusters were defined as school-catchment areas or settlements with one public primary school. This was necessary to ensure that girls had access to a school and that they had access to group meeting locations. A total of 80 clusters were identified in Wajir and stratified by district: Wajir West (20 clusters), Wajir East (28 clusters), and Wajir South (32 clusters). Wajir North was excluded because the implementing partner does not operate in that area. Within the remaining three districts, communities that were excluded were: small villages with less than 8 eligible girls, urban areas, peri-urban areas with more than one primary school, and villages that are on the Kenya-Somali border or other villages where the implementing staff have limited access due to security reasons.

Propensity-score matching on baseline indicators will be used to select comparison girls from the external control site to minimize risk of selection bias when making comparisons with girls in the program sample. Therefore, we do not report on the Nairobi external control in this report.

\section{Study Population}

The primary target population is girls 11-14 who were residing within selected study sites at the time of the baseline survey and who were not in boarding school at the time of the listing and/or at the time of the survey. ${ }^{f}$ Parents, guardians, and community members within these sites are targeted within the violence-prevention intervention.

In Kibera, individual-level randomization provided greater power to detect differences. The sample size was calculated based on power calculations to determine the number of clusters and number of girls needed in each cluster to observe the desired change in key outcomes: timing of first birth and years of schooling. Data from the Nairobi Cross-Sectional Slum Survey were used to obtain estimates used for the power calculations. ${ }^{15}$ The target sample estimates

\footnotetext{
f For Kibera, because sampling was conducted based on a listing of households over a period of severa months, the age cutoffs include girls who had not yet turned 15 as of November 20, 2015, and were at least 11 years of age by January 18, 2015.
} 
required a sample size of 750 girls per arm at baseline (600 girls per arm at endline, assuming a loss of $20 \%$ by endline). However, due to the higher proportion of noneligible girls (i.e., in boarding school or moved out of the study area), the actual sample included approximately 600 girls per arm at baseline (480 girls per arm at endline, assuming a loss of $20 \%$ by endline). Upon learning of the high number of noneligible girls, several options were discussed with the Expert Research Committee (ERC) regarding strategies to increase the number of girls. Of these, the selected strategy was to conduct replacement of noneligible girls with eligible girls in the same household, selected at random.

For cluster randomization in Wajir, the estimate of the intra-cluster correlation (ICC) and the baseline estimates for childbearing and education were based on data on the Northeastern Province from the 2008/09 Kenya Demographic and Health Survey. The target estimate was a sample size of 20 clusters per arm and 32 girls per cluster at baseline ( 40 girls per cluster at endline, assuming a loss of $20 \%$ by endline). However, due to variations between population estimates and the actual number of eligible girls residing in these communities at the time of the survey, the final sample included 20 clusters per arm with an average of 27 girls per cluster (22 at endline, assuming a loss of 20\%). Table 2 shows the minimum detectable differences with power of 0.80 and a significance level of 0.05 for the target estimates and actual sample sizes for Kibera and Wajir.

These effects are considered attainable for the achieved sample, considering the multi-sectoral approach that addresses several of the factors that increase risk of early childbearing in these young populations in which very few girls have begun childbearing. Two large cash transfer programs in Kenya and Malawi using an RCT design obtained similar results using a singlesector approach. The Kenya Cash Transfer for Orphans and Vulnerable Children showed a reduced likelihood of pregnancy by 5 percentage points at the Year Four follow-up survey among women aged 12-24. ${ }^{16}$ The Zomba Cash Transfer Program in Malawi, a randomized Conditional Cash Transfer targeting young women aged 13-24, showed a reduction of 5.1 percentage points in the likelihood of becoming pregnant over one year for girls who were out of school at baseline. ${ }^{4}$

TABLE 2 Minimum detectable differences for target sample estimates and actual sample sizes

\begin{tabular}{|c|c|c|c|}
\hline SITE & TARGET SAMPLE & ACTUAL SAMPLE & MINIMUM DETECTABLE DIFFERENCES \\
\hline Kibera & $\begin{array}{l}750 \text { girls per arm } \\
\text { at baseline }\end{array}$ & $\begin{array}{l}600 \text { girls per arm } \\
\text { at baseline }\end{array}$ & $\begin{array}{l}\text { Assuming that } 15.4 \% \text { of girls in the violence preven- } \\
\text { tion only arm would have given birth by endline: we } \\
\text { would detect a statistically significant difference of } 6.3 \\
\text { percentage points between the violence prevention } \\
\text { only arm and each of the other three arms } \\
\text { Assuming a correlation coefficient of } 0.33 \text {, we would } \\
\text { detect a statistically significant difference of } 0.55 \\
\text { grade of schooling between any two arms }\end{array}$ \\
\hline Wajir & $\begin{array}{l}20 \text { clusters per } \\
\text { arm, } 40 \text { girls at } \\
\text { baseline }\end{array}$ & $\begin{array}{l}20 \text { clusters per } \\
\text { arm, } 27 \text { girls at } \\
\text { baseline }\end{array}$ & $\begin{array}{l}\text { Assuming that } 17.6 \% \text { of girls in the violence preven- } \\
\text { tion only arm would have given birth by endline, we } \\
\text { would detect a statistically significant difference of } 6.9 \\
\text { percentage points between the violence prevention } \\
\text { only arm and each of the other three arms } \\
\text { Assuming a correlation coefficient of } 0.26 \text {, we would } \\
\text { detect a statistically significant difference of } 0.49 \\
\text { grade of schooling between any two arms }\end{array}$ \\
\hline
\end{tabular}




\section{BASELINE SURVEY}

\section{Household Listing}

In urban slums, a household listing was conducted between November 2014 and January 2015 in the selected areas of Kibera, using maps obtained from the Kenya National Bureau of Statistics and with the assistance of local leaders, to identify eligible girls between the ages of 11 and 14. The listing was conducted using Open Data Kit (ODK) software on Android tablets. Enumerators assigned a unique serial number to each household, and if an adult was available they administered a brief screening questionnaire to ascertain whether there was an eligible girl residing within the household. The preferred respondent was the household head, or if unavailable, the second choice was a spouse of the household head, and the third choice was another adult residing in the household. Similar to the Demographic and Health Surveys (DHSs), a household was defined as one that shares a kitchen (pot) and has the same household head. Household members were defined as individuals who live or intend to live in the household for 6 months or more, including any school children who might not have been present at the time of the interview because schools were closed but reside there when school is in session.

A screener was conducted to identify girls in the target population. The five screening questions were: 1) Is the head of the household male or female? 2) How many total people live in the household? 3) How many adults age 18 and above live in this household? 4) How many girls age 10-15 live in this household? 5) How many boys age 10-15 live in this household? All households that answered one or more to question 4 continued to complete a roster and a brief household survey. The roster listed all household members and included questions on age, education, marital status, parents' survivorship, and number of living children. The household survey included questions on ownership of household assets, source of drinking water, type of toilet facility, number of sleeping rooms, and the main material of the floor and the roof of the structure.

A total of 64,946 unique households were listed in Kibera and the screener was completed with a consenting adult in $41 \%$ of these with less than $1 \%$ refusals. Although not completed in the remaining $58 \%$, the field protocol was designed to ensure age-eligible girls were not missed even when the screener was not completed directly with a household member. In particular, a research assistant visited each household three times and if no one was available inquired from neighbors as to whether there were children between the ages of 10 and 15 residing in the household. Households with children were revisited before the research team proceeded to a different enumeration area. The listing resulted in 5,134 households with at least one girl between the ages of 10 and 15, and 4,314 girls between the ages of 11 and 14 .

In Wajir, a different, paper-based listing procedure was used to quickly identify eligible girls in the field, as it was not necessary to randomly select girls for program participation due to the cluster-randomization design. Enumerators visited each household within selected villages, assigned it a unique serial number, and conducted a brief screening interview to obtain the name of the head of the household as well as the number of boys and girls aged 10-15 years residing in the household. The same definitions for a household and household member were used as described above, as well as the same preference for respondent. For households with one or more girls between the ages of 10 and 15, a cover sheet was filled out in which enu- 
merators listed the name, age, and sex of each girl and boy in that age group. After listing the entire village, the team leaders collected the cover sheets and counted the number of sheets with a girl in the target age range of 11 to 14 . A total of 4,152 eligible girls were identified in 80 villages, ranging from 9 girls to 181 girls per village.

\section{Selection for Baseline Sample}

In Kibera, a total of 4,314 girls were determined to be between the ages of 11 and 14 at the time of the listing (based on reported or calculated age). Of these, 574 girls were excluded because they were in boarding school or residing outside of Kibera for school or other purposes. They were excluded because the aim was to obtain a sample of eligible girls according to the program criteria (i.e., girls who would be available to participate in program interventions). Of the remaining 3,740 girls, one girl per household was randomly selected for the sample, resulting in a sample of 3,296 individual girls with 444 siblings within the target age range.

In Wajir, out of 4,152 eligible girls, 2,923 were selected for the baseline survey. Selection was determined by the number of eligible girls (11-14) in each cluster/village. For villages with less than 40 households that have an eligible girl, all households were selected for the baseline sample, and all eligible girls within those households were interviewed. In villages with 40 or more households having an eligible girl, team leaders used lists of random numbers to randomly select 40 households, and to randomly select one girl within each household for the baseline survey sample.

\section{Randomization to Study Arms}

Assignment of clusters/individuals to study arms was conducted in the form of a public lottery to increase transparency and minimize questions and distrust regarding the selection process. In Kibera, girls were randomly assigned to study arms during a Kibera External Advisory Committee $^{g}$ meeting attended by local stakeholders and leaders. An Excel file with a list of girls' ID numbers was projected on the screen, and an Excel formula was used to generate a random number for each girl. The list was sorted in ascending order of the random number and divided girls into four equal groups based on this order. Four stakeholders volunteered to randomly pick a piece of paper from a bag with one of the four study arms written on it, and this arm was assigned to the particular group.

In each district in Wajir, a meeting was held with stakeholders and leaders at the sub-county level, as well as one representative from each of the clusters. A list of all the clusters in the district in alphabetical order was pinned on the wall, and a representative from each village was asked to pick a piece of paper from a transparent container containing an equal number of papers listing the four study arms. Once the representative picked a paper, he/she was asked to publicly announce the arm selected, and it was pasted on the wall next to the name

g Kibera External Advisory Committee is a group convened by Plan International (implementing partner in Kibera) that includes key stakeholders at the county level for the purpose of providing general guidance and promoting research uptake. A parallel External Advisory Committee for Wajir County was convened by Save the Children (implementing partner in Wajir). 
of the village. After all the villages had selected an arm, each representative was asked to sign the paper to acknowledge acceptance of the public lottery results.

\section{Data Collection}

The baseline survey was conducted between February and May 2015 in Kibera and Wajir.

Female survey interviewers with at least a diploma or Bachelor's degree were recruited from each of the project locations. Supervisors with considerably more research experience were recruited to oversee interviewers, led by a study coordinator in each site. Each supervisor was tasked with overseeing a team of 12 interviewers in Kibera and 7 interviewers in Wajir. All interviewers attended an 8-day training on the details of the survey instruments. Separate trainings were conducted for the Wajir and Nairobi sub-studies due to the different survey languages and to reduce interviewers' travel costs. In Wajir, interviewers also participated in an extra four-day refresher training because of a lag-time between the initial training and the start of data-collection activities due to security concerns. Training included an item-by-item review of the research instruments, mock interviews, and a practice interview done outside the study area. Supervisors attended the training as well as an additional one-day training devoted to supervision, data quality, and troubleshooting issues in the field. In addition, a data manager and study coordinator accompanied the teams during data collection, to review the quality of the surveys, address trouble areas, and send the data to the investigators on a daily basis for review.

Interviewers visited each household to conduct the interview with selected respondents. Before administering the survey, informed consent was obtained from parents/guardians of girls and from the girls themselves. Parental consent was not required from emancipated minors (e.g., married girls). To the extent possible, baseline interviews were conducted in an area with visual and auditory privacy. If the respondent was not present at the household on the day of the interviewer's visit, the interviewer was instructed to pay at least three visits to the household in order to locate and interview the selected respondent, similar to the procedure used in the DHS. When necessary, interviewers also interviewed girls at school after obtaining consent from parents and school administrators. In Kibera, approximately 157 selected girls who were not interviewed for various reasons (mostly because they were ineligible) were replaced by an eligible sister. If there was more than one eligible sister, the replacement was selected randomly. In Wajir, replacement was only implemented in villages with 40 or more eligible girls. Each household in which a selected girl was not interviewed was replaced by another household randomly selected from the pool of eligible girls not previously selected. Due to low response rates in Wajir, enumerators also returned to villages with the lowest response rates in May 2015 to attempt to find 282 girls who had migrated because of water shortages. Out of these 282 girls, only 85 were interviewed during this round of data collection.

Survey instruments were implemented by electronic data capture: Computer-Assisted PersonalInterviewing (CAPI) on tablet computers. CAPI is a process of data capture in which the interviewer reads the question from a computer screen and enters the participant's response directly into a handheld or tablet device. 


\section{Research Instruments}

The quantitative survey ${ }^{\mathrm{h}}$ covered topics such as: socio-demographic characteristics; schooling history; education attainment: social assets and networks, self-efficacy, locus-of-control, financial literacy, savings and livelihoods, marital and child-bearing aspirations, birth history, experience of physical and sexual harassment and violence, attitudes on FGM, self-reported health and nutrition, reproductive health knowledge, HIV and AIDS risk perception, comprehension in local language and English, excerpts from official mathematics assessments multiple standards (grades), and cognitive testing. In Wajir, the comprehensive survey also included household roster and other household characteristics collected in the Nairobi listing. The survey was translated into Swahili and Somali, and pilot-tested and revised based on feedback from interviewers before data collection began.

In addition, a short household survey was conducted with the head of household or adult providing consent at the time of the interview, to collect information about the household's experience of major shocks, receipt of other cash transfer, participation in other programs, and gender norms.

\section{Response Rates}

In Kibera, out of the sample of 3,296 girls approximately $21 \%$ were confirmed to be ineligible during baseline data collection based on age, residence in the community, and being in boarding school. Of the eligible 2,606 girls, approximately $92 \%$ or 2,402 girls were interviewed. The reasons for nonresponse included refusals by the parent, spouse, or girl herself, incapacitation, death, or inability to locate the household or the girl. The final analytical sample consisted of 2,394 girls after further excluding 8 interviewed girls who were ineligible based on age or area of residence. The research sample included some girls who were age 14 at the time of the listing but had turned 15 by the time they were interviewed.

In Wajir, out of 2,923 girls selected for an interview approximately $21 \%$ were confirmed to be ineligible during baseline data collection, mainly based on residence in the community at the time of the survey. Of the eligible 2,297 girls, approximately $93 \%$ or 2,150 were interviewed and included in the final analytical sample. The reasons for nonresponse included refusals, incapacitation, death, and inability to locate the girl.

\section{Analysis}

The baseline report includes frequencies of selected indicators and cross-tabulations by age using STATA. For categorical variables, significance tests comparing younger girls (ages 11-12) and older girls (ages 13-14) were estimated using Pearson's Chi Square. For continuous variables, linear regression models were estimated using options for obtaining robust standard errors in the Kibera dataset and adjusting for clustering by village in the Wajir dataset.

\footnotetext{
h Research instruments are available for download in the Resources section of the Adolescent Girls Initiative-Kenya webpage at: http://www.popcouncil.org/research/adolescent-girls-initiative-actionresearch-program.
} 
Upon collecting three rounds of data (baseline, endline, and follow-up), the program evaluation will examine the impact of the average treatment effect across intervention packages while identifying the causal mechanisms driving that impact. This will be done using an intent-to-treat analysis, estimating the average increase in outcomes of girls in the baseline survey in one arm to the average outcomes of girls in another arm. Therefore, all girls in the original sample who are randomized to study arms will remain part of the study despite noncompliance, protocol deviations, withdrawal, and anything else that happens after randomization. This analysis technique provides more accurate estimates for project scale-up, by accepting that not all girls would agree to participate in the study, and noncompliance and protocol deviations are likely to occur in general practice in these settings.

\section{Program Intervention}

In Kibera, all girls in the research sample were invited to participate in the program, as well as other girls in the same households who were between the ages of 11 and 14 at the time of the household listing, residing in the study area, and not in boarding school. These girls were assigned the same study arms as the study participant in the household. In Wajir, all girls in the research sample were invited, as well as all other girls between the ages of 11 and 14 in selected clusters who were residing in the study area and attending the public primary school in that cluster, or a secondary school elsewhere. Registration for participation in program interventions was occurring at the time of the publication of this report, therefore data on participation rates were not yet available.

TABLE 3 Number of girls in research and program samples by site

\begin{tabular}{lcc}
\hline SITE & FINAL STUDY SAMPLE & GIRLS ELIGIBLE FOR PROGRAM \\
\hline Kibera & 2394 & 2777 \\
Wajir & 2150 & 4155 \\
Total & 4544 & 6932 \\
\hline
\end{tabular}




\section{Baseline Results}

The AGI-K baseline survey report describes baseline characteristics of younger adolescent girls ages 11-14 in Kibera and Wajir based on samples of 2,394 respondents in Kibera and 2,150 respondents in Wajir. The socioeconomic characteristics of respondents and their households are based on samples of parents and guardians who completed the household survey $(2,375$ in Kibera and 2,122 in Wajir). This is equivalent to 99\% of girls in the sample in both Wajir and Kibera who had a household survey completed. Due to having more than one girl per household in Wajir, there were 1,891 unique household surveys completed.

The following baseline survey results give context to younger adolescent girls' realities in Kibera and Wajir. The two locations differ greatly with respect to economic opportunities, geography, religion, and culture, so a direct comparison is not possible, but some of the stark contrasts provide further meaning to the varying experiences of younger adolescent girls in Kenya. The results section begins with a description of the socio-demographic characteristics of respondents and their households, followed by results for each of the four sectors of the AGI-K interventions: education, wealth creation, health, and violence prevention. The tables throughout provide an overview of the sample characteristics at baseline in both Kibera and Wajir.

\section{SOCIO-DEMOGRAPHIC CHARACTERISTICS OF RESPONDENTS AND HOUSEHOLDS}

The socio-demographic characteristics of households and respondents in Wajir and Kibera are presented in this section. The tables highlight some of the differences and similarities between the two study sites.

\section{Background Characteristics of Girls}

Table 4 presents the distribution of households by selected demographic characteristics. Results show that the sample of girls in Kibera was slightly older (52\% aged 13-14 years). The majority of the respondents in Kibera were Christians, with $62 \%$ being Protestants and 23\% reporting as Catholic. The ethnic group most dominant among girls living in Kibera was Luo (36\%), followed by Luhya (32\%) and Kamba (9\%). In Wajir, almost $100 \%$ of respondents reported being Muslims, and the most dominant ethnic group was Somali (93\%), followed by respondents who identified with either Mijikenda, Swahili, or Taita Taveta (6\%). Only $2 \%$ of girls in Kibera and $0.05 \%$ of girls in Wajir declared that they had no religious affiliation. 
TABLE 4 Percent distribution of girls aged 11-15, by selected background characteristics, Kibera and Wajir, 2015

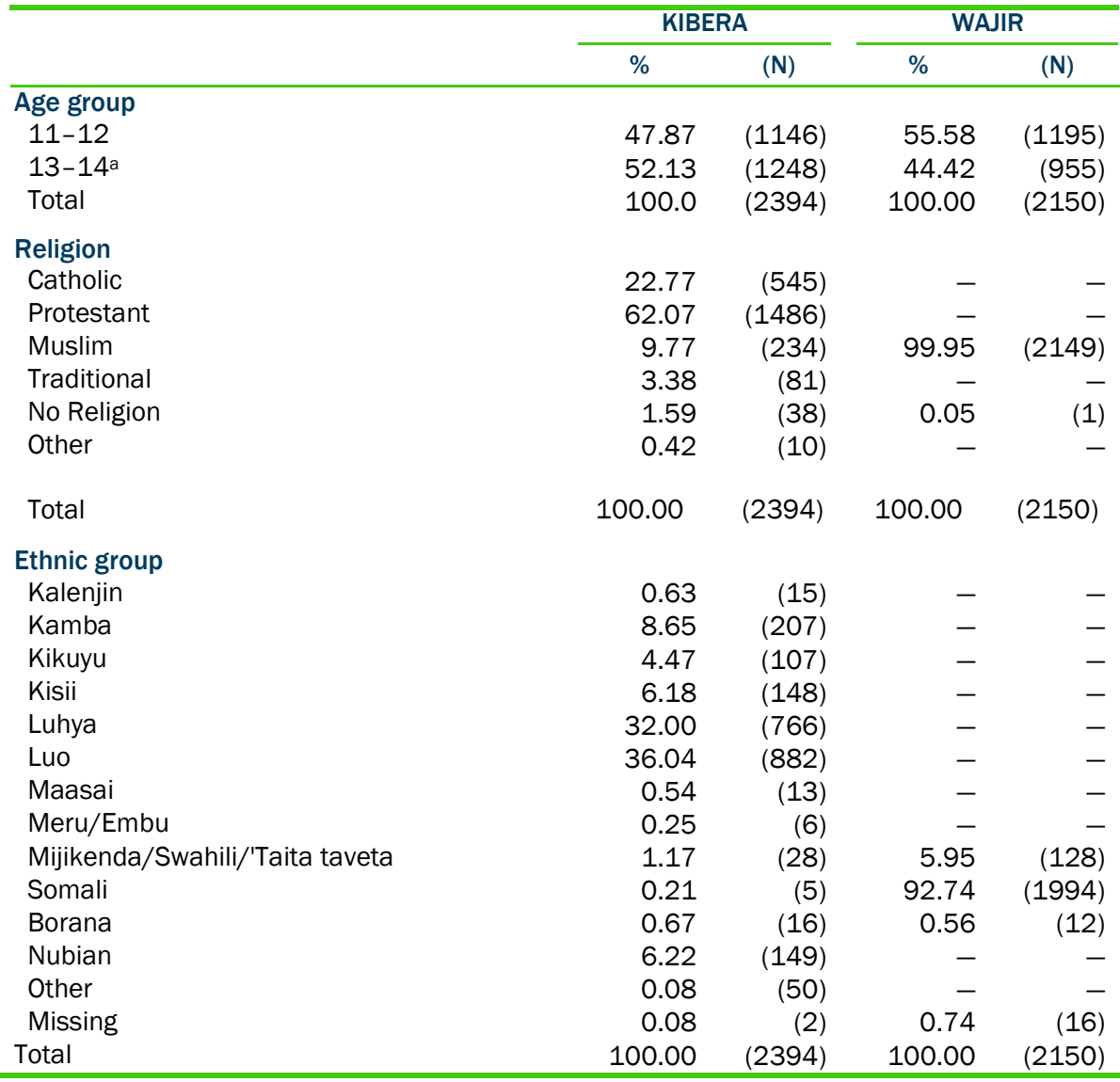

a In Kibera, a small percentage of girls in the sample had turned 15 years by the time they were interviewed for the baseline survey. In Wajir, the household listing took place simultaneously with the baseline survey, therefore there was not time for girls to age from 14 to 15 years.

A dash means that data are unavailable or cases equal zero in those cells.

\section{Characteristics of Households}

Figure 4 shows the distribution of young people interviewed during the baseline survey according to the survival status of their parents for Kibera and Wajir. About $76 \%$ of girls in Kibera reported that both parents were still living, with the remainder of girls reporting that their mother (4\%) or father (15\%) was deceased, or that they were double orphans (4\%). In Wajir, $88 \%$ of girls reported both parents were living, approximately $7 \%$ of girls reported the father was deceased, $4 \%$ of girls reported that the mother was deceased, and five girls $(0.2 \%)$ reported both parents were deceased. 
FIGURE 4 Percent distribution of adolescents aged 11-14 years by parental survival status, Kibera and Wajir, 2015

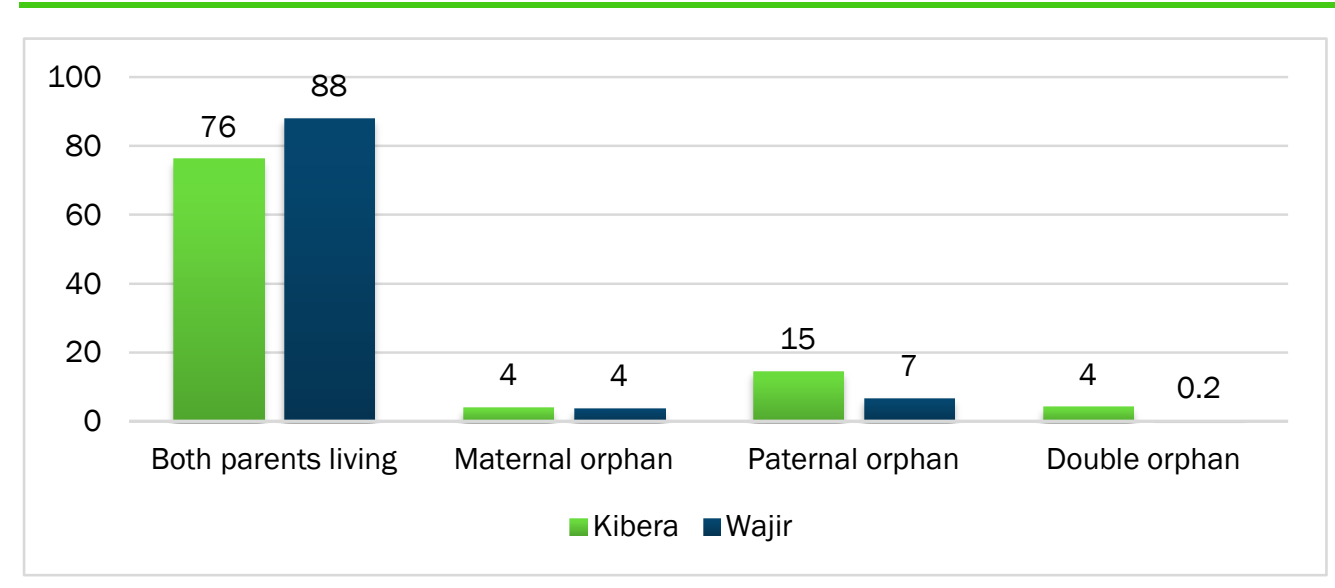

Capturing parental presence in the lives of young adolescents is important, as living with a parent affects young people's behavior such as initiation of sexual intercourse, and the antecedent consequences, such as unintended pregnancy. ${ }^{17}$ Figure 5 presents the distribution of young people interviewed at baseline according to their living arrangements in Kibera and Wajir. Fiftytwo percent of adolescent girls in Kibera were living with both parents, one in four were living with their mother only, and about $6 \%$ lived with their father only. About $16 \%$ of girls in Kibera reported not living with a parent. In Wajir, almost three-quarters of girls were living with both parents, $11 \%$ lived with a mother only, $6 \%$ with a father only, and $8 \%$ lived with neither parent.

FIGURE 5 Percent distribution of the living arrangements of adolescents aged 11-14 years, Nairobi and Wajir, 2015

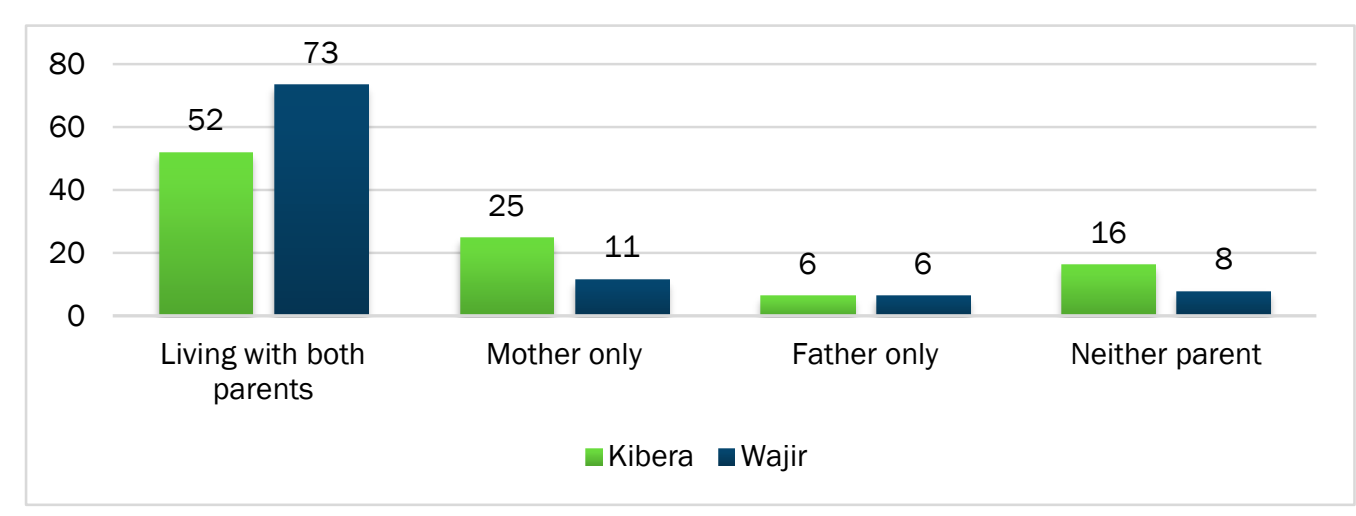

Family background, especially parents' educational attainment is important in determining children's educational attainment, especially years of schooling. ${ }^{18}$ Similarly, parental socioeconomic status (SES) may not only impact the health of the parent themselves but also the health outcomes of their children. This association is partly explained by the fact that educated parents tend to have better health knowledge and are more likely to practice better health behaviors. ${ }^{19}$

Table 5 presents the percent distribution of households by selected demographic characteristics. 
TABLE 5 Educational attainment of parents of respondents, Kibera and Wajir, 2015 (percent)

\begin{tabular}{|c|c|c|c|c|}
\hline & \multicolumn{2}{|c|}{$\operatorname{KIBERA}(\mathrm{N}=2375)$} & \multicolumn{2}{|c|}{ WAJIR $(N=1891)$} \\
\hline & $\%$ & $(\mathrm{~N})$ & $\%$ & $(\mathrm{~N})$ \\
\hline \multicolumn{5}{|c|}{ Mother's educational attainment } \\
\hline No education & 4.34 & $(103)$ & 98.84 & $(1869)$ \\
\hline Some primary & 30.11 & $(715)$ & 0.63 & $(12)$ \\
\hline Primary completed & 34.40 & (817) & 0.21 & (4) \\
\hline Some secondary & 11.96 & $(284)$ & -- & - \\
\hline Secondary completed & 10.86 & $(258)$ & 0.05 & (1) \\
\hline More than secondary & 2.15 & $(51)$ & -- & - \\
\hline Don't know & 6.15 & $(146)$ & 0.05 & (1) \\
\hline Missing & 0.04 & $(1)$ & 0.21 & (4) \\
\hline \multicolumn{5}{|c|}{ Father's educational attainment } \\
\hline No education & 2.48 & $(59)$ & 95.77 & (1811) \\
\hline Some primary & 16.04 & $(381)$ & 1.32 & $(25)$ \\
\hline Primary completed & 23.54 & (559) & 0.63 & $(12)$ \\
\hline Some secondary & 11.37 & $(270)$ & 0.16 & (3) \\
\hline Secondary completed & 25.60 & $(608)$ & 0.74 & $(18)$ \\
\hline More than secondary & 3.62 & (86) & 0.95 & $(4)$ \\
\hline Don't know & 17.31 & (411) & 0.21 & (4) \\
\hline Missing & 0.04 & (1) & 0.21 & - \\
\hline
\end{tabular}

In Kibera, about $4 \%$ of mothers had no education, $30 \%$ had completed some primary school, and about 1 in 3 had completed primary school (34\%). About 11\% of mothers in Kibera had some secondary schooling (forms 1-3), with a similar proportion reporting a completed a secondary education (form 4). About $2 \%$ of mothers in our sample reported a secondary education and above. Fathers in Kibera tended to report slightly higher educational attainment compared with mothers. About $16 \%$ of fathers reported some primary education, $24 \%$ reported a completed primary school education, and 11\% reported some secondary education. About 1 in 4 fathers (26\%) reported a completed secondary education, while another $4 \%$ had an educational attainment higher than secondary. Similar to mothers, about 3\% of fathers in Kibera reported that they had never attended school. In Wajir, about $99 \%$ of the mothers and $96 \%$ of the fathers reported that they had never attended school.

\section{NORMS AROUND GENDER AND GENDER ROLES}

Parental gender roles and attitudes influence the way children and young people behave and the way they respond to their surrounding environment. ${ }^{20}$ Household survey respondents were asked whether they agreed or disagreed with a series of hypothetical statements regarding norms around gender and gender roles. Results are presented in Table 6 by the sex of the respondent, for both Kibera and Wajir.

As expected, responses to some of the statements varied by whether the respondent was male or female, as well as by study area. However, respondents in Wajir tended to have similar responses irrespective of gender. 
Males (8\%) in Kibera were significantly more likely to agree with the statement that boys should be sent to school before girls if the family is poor and cannot send all children to school, compared with their female counterparts (5\%). There was no significant difference in the response to this statement among respondents in Wajir. In Kibera, 31\% of women compared with their male counterparts (25\%) were significantly more likely to agree with the statement that men rape girls because they cannot control themselves. In Wajir, $63 \%$ of women were significantly more likely to agree with the statement that if a girl is raped, the matter should be settled between the girl's family and the man's family, compared with $53 \%$ of the men in the sample. In Kibera, 15\% of women agreed to this statement, compared with $10 \%$ of their male counterparts who agreed to the same.

TABLE 6 Percentage of household survey respondents who agreed or disagreed with gender norm statements, by sex of respondent, Kibera and Wajir, 2015

\begin{tabular}{|c|c|c|c|c|c|c|c|c|}
\hline & \multicolumn{4}{|c|}{ KIBERA $(\mathrm{N}=2375)$} & \multicolumn{4}{|c|}{ WAJIR (N = 1887*) } \\
\hline & MALE & FEMALE & P-VALUE & (N) & MALE & FEMALE & P-VALUE & $(\mathrm{N})$ \\
\hline \multicolumn{9}{|c|}{$\begin{array}{l}\text { 1. When a family is poor and cannot send } \\
\text { all children to school, boys should be } \\
\text { sent before girls. }\end{array}$} \\
\hline Agree & 8.16 & 5.02 & & (133) & 27.39 & 28.01 & & $(525)$ \\
\hline Disagree & 91.84 & 94.98 & 0.009 & (2242) & 72.61 & 71.99 & 0.782 & (1362) \\
\hline \multicolumn{9}{|c|}{$\begin{array}{l}\text { 2. If a rich man offers to marry a } 16 \text {-year- } \\
\text { old girl, she should leave school and get } \\
\text { married. }\end{array}$} \\
\hline Agree & 0.45 & 0.62 & & (14) & 15.55 & 15.52 & & (293) \\
\hline Disagree & 99.55 & 99.38 & 0.679 & (2361) & 84.45 & 84.48 & 0.461 & (1594) \\
\hline \multicolumn{9}{|c|}{$\begin{array}{l}\text { 3. Men rape girls because they cannot } \\
\text { control themselves. }\end{array}$} \\
\hline Agree & 24.49 & 31.23 & & $(712)$ & 23.50 & 21.95 & & (423) \\
\hline Disagree & 75.51 & 68.77 & 0.005 & (1663) & 76.50 & 78.1 & 0.626 & (1464) \\
\hline \multicolumn{9}{|c|}{$\begin{array}{l}\text { 4. If a girl is raped, the matter should be } \\
\text { settled between the girl's family and the } \\
\text { man's family. }\end{array}$} \\
\hline Agree & 9.75 & 15.05 & & (334) & 52.83 & 62.68 & & (1127) \\
\hline Disagree & 90.25 & 84.95 & 0.004 & (2041) & 47.17 & 37.32 & 0.000 & $(760)$ \\
\hline \multicolumn{9}{|c|}{$\begin{array}{l}\text { 5. It is the [girl's] duty to do what a [man] } \\
\text { wants in a marriage. }\end{array}$} \\
\hline Agree & 38.10 & 37.95 & & (902) & 62.01 & 52.23 & & (1041) \\
\hline Disagree & 61.90 & 62.05 & 0.956 & (1473) & 37.99 & 47.77 & 0.000 & $(846)$ \\
\hline \multicolumn{9}{|c|}{$\begin{array}{l}\text { 6. If a [girl] got/had gotten pregnant, you } \\
\text { would force/have forced her to get } \\
\text { married. }\end{array}$} \\
\hline Agree & 3.40 & 2.79 & & (69) & 27.21 & 31.11 & & (565) \\
\hline Disagree & 96.60 & 97.21 & 0.492 & (2306) & 72.79 & 68.89 & 0.090 & $(1322)$ \\
\hline \multicolumn{9}{|c|}{$\begin{array}{l}\text { 7. You would like/have liked your daugh- } \\
\text { ter to finish secondary school before } \\
\text { getting married. }\end{array}$} \\
\hline Agree & 92.29 & 93.74 & & (2220) & 61.31 & 76.08 & & (1352) \\
\hline Disagree & 7.71 & 6.26 & 0.265 & $(155)$ & 38.69 & 23.92 & 0.000 & (535) \\
\hline \multicolumn{9}{|c|}{$\begin{array}{l}\text { 8. You would want/have wanted your } \\
\text { daughter to get married if you needed } \\
\text { financial support. }\end{array}$} \\
\hline Agree & 0.91 & 2.12 & & (45) & 22.26 & 19.68 & & (386) \\
\hline Disagree & 99.09 & 97.88 & 0.092 & (2330) & 77.74 & 80.32 & 0.203 & (1501) \\
\hline
\end{tabular}

*4 households with missing data. 
More than a third of men and women (38\%) in Kibera agreed that it is the girl's duty to do whatever a man wants in marriage. In Wajir, about $62 \%$ of males agreed to this statement compared with $52 \%$ of women who agreed to the same. Women (31\%) in Wajir were slightly more likely to agree that a girl should be forced to get married if she got or had gotten pregnant, compared with male counterparts (27\%). A high proportion of females in both Kibera (94\%) and Wajir (76\%) agreed that daughters should finish secondary school before getting married, compared with $92 \%$ of males in Kibera and $61 \%$ of males in Wajir.

\section{HOUSEHOLD AMENITIES AND DURABLE GOODS}

Table 7 presents the distribution of basic amenities among respondents in Kibera and Wajir. In Kibera, $94 \%$ of households reported access to electricity. Further, the majority of households used public taps (95\%) not piped into compound or residence. In Wajir, sources of drinking water were more varied. A high proportion of households accessed drinking water from a borehole (31\%), followed by dug wells (21\%), public taps (18\%), and small tankers or trucks (16\%).

With regard to sanitation facilities, a higher proportion of households in Kibera reported access to some sanitation facility. Specifically, about 1 in 2 households (51\%) reported use of ventilated pit latrines, followed by traditional pit latrines (23\%). It should be noted that most of the pit latrines in Kibera, as in other slums in Nairobi, are shared by multiple households and are often unusable or unsanitary. ${ }^{15,21}$ About $20 \%$ of households reported access to flush toilets, though less than $4 \%$ of that is piped to a sewer system. Most houses in Kibera have cement floors (74\%) and corrugated iron as material for the roof (97\%), with the majority of households reporting an average of about one sleeping room in the house.

In Wajir, less than $1 \%$ of households reported access to electricity. Eighty-five percent of households in Wajir report no sanitation facility and most reported use of an open field or bushes. Most houses in Wajir use mud, sand, or dung as the main materials for both the floors (96\%) and roof (89\%), with the majority of households also reporting an average of about one sleeping room in the house. 
TABLE 7 Percent distribution of households by amenities, Kibera and Wajir, 2015

\begin{tabular}{|c|c|c|c|c|}
\hline \multirow[b]{2}{*}{ CHARACTERISTIC } & \multicolumn{2}{|c|}{ KIBERA ( $\mathrm{N}=2375)$} & \multicolumn{2}{|c|}{ WAJIR (N = 1891) } \\
\hline & & $(\mathrm{N})$ & & (N) \\
\hline \multicolumn{5}{|l|}{ Electricity* } \\
\hline Yes & 93.64 & $(2224)$ & 0.42 & (8) \\
\hline No & 6.36 & $(151)$ & 99.58 & $(1879)$ \\
\hline \multicolumn{5}{|l|}{ Source of drinking water* } \\
\hline Piped to dwelling & 0.38 & (9) & 0.79 & (15) \\
\hline Piped into compound & 3.58 & (85) & 1.06 & $(20)$ \\
\hline Public tap & 95.28 & (2263) & 18.25 & (344) \\
\hline Borehole & 0.42 & $(10)$ & 31.25 & $(591)$ \\
\hline Dug well & 0.04 & (1) & 20.69 & $(390)$ \\
\hline Protected/unprotected spring water & 0.00 & $(0)$ & 3.34 & $(63)$ \\
\hline Tanker/truck & 0.17 & $(4)$ & 16.34 & $(308)$ \\
\hline Bottled water & 0.08 & $(2)$ & 0.00 & $(0)$ \\
\hline Surface water & 0.04 & (1) & 8.17 & $(154)$ \\
\hline Other & - & - & 0.11 & (2) \\
\hline \multicolumn{5}{|l|}{ Sanitation facility } \\
\hline Flush toilet & 19.66 & $(467)$ & 2.22 & $(42)$ \\
\hline Traditional pit latrine & 22.74 & $(540)$ & 4.55 & (86) \\
\hline Ventilated pit latrine & 50.91 & (1209) & 8.46 & $(160)$ \\
\hline Bucket/composting/hanging toilet & 1.14 & $(27)$ & 0.32 & (6) \\
\hline No facility/bush & 5.56 & $(132)$ & 84.45 & $(1597)$ \\
\hline \multicolumn{5}{|l|}{ Main floor material } \\
\hline Mud/sand/dung & 23.28 & $(553)$ & 95.51 & $(1806)$ \\
\hline Wood planks/wood/vinyl/tiles & 0.29 & $(7)$ & 1.06 & $(20)$ \\
\hline Finished: cement/tiles/carpet & 74.15 & (1761) & 2.86 & (54) \\
\hline Other & 2.27 & $(54)$ & 0.58 & (11) \\
\hline \multicolumn{5}{|l|}{ Main roof material } \\
\hline Dung/thatch/mud/grass & 1.01 & (24) & 88.95 & $(1682)$ \\
\hline Corrugated iron & 97.05 & (2305) & 10.26 & (194) \\
\hline Finished roofing & 0.25 & (6) & 0.48 & (9) \\
\hline Other & 1.68 & $(40)$ & 0.32 & (6) \\
\hline \multicolumn{5}{|l|}{ Number of sleeping rooms* } \\
\hline $0-1$ & 71.33 & (1694) & 88.68 & $(1677)$ \\
\hline 2 & 24.46 & $(581)$ & 10.15 & $(192)$ \\
\hline $3+$ & 4.21 & $(100)$ & 0.90 & $(17)$ \\
\hline
\end{tabular}

*Does not sum to $100 \%$ because of missing data.

A dash means that data are unavailable or cases equal zero in those cells

Table 8 presents the percent distribution of households in the sample by possession of selected consumer durable goods in Kibera and Wajir. Information on household possession of consumer durable goods and other household assets listed above can be used as a proxy indicator to assess the socioeconomic status of the household. ${ }^{22}$ The most common durable goods in Kibera are mobile phones (98\%), televisions (76\%), radios (68\%), irons (41\%), and mosquito nets (40\%). In Wajir, the most common durable goods were mobile phones (48\%), mosquito nets (40\%), radio sets (23\%), and animal drawn carts (19\%). 
TABLE 8 Percent distribution of households by durable goods, Kibera and Wajir, 2015

\begin{tabular}{|c|c|c|c|c|}
\hline \multirow[b]{2}{*}{ DURABLE GOOD } & \multicolumn{2}{|c|}{ KIBERA $(\mathrm{N}=2375)$} & \multicolumn{2}{|c|}{ WAJIR (N = 1891*) } \\
\hline & $\%$ & (N) & $\%$ & (N) \\
\hline Radio & 67.75 & (1609) & 23.27 & (440) \\
\hline Television & 76.04 & (1806) & 1.75 & (33) \\
\hline Mobile phone & 98.44 & (2338) & 48.28 & (913) \\
\hline Refrigerator & 6.36 & (151) & 0.66 & (13) \\
\hline Iron & 41.09 & $(976)$ & 0.69 & (13) \\
\hline Mosquito nets & 39.45 & (937) & 39.87 & (754) \\
\hline Solar panel & 1.89 & (45) & 0.79 & (15) \\
\hline Bicycle & 7.58 & $(180)$ & 0.16 & (3) \\
\hline Motorcycle & 1.26 & (30) & 0.16 & (3) \\
\hline Private car & 1.09 & (26) & 1.16 & (22) \\
\hline Animal-drawn cart & 0.46 & (11) & 18.93 & (358) \\
\hline
\end{tabular}

*4 households with missing data.

\section{HOUSEHOLD FINANCIAL STATUS}

To further assess the socioeconomic status of the households in the study sample, several survey questions were asked on the employment status of parents, shocks to households (loss of jobs), savings, and programs to support households from organizations. Table 9 shows the percent distribution of households by financial status.

Respondents were asked if their household had been provided with any cash or support in kind (grains, seeds, poultry, livestock, or food items) free of charge in the last year. Results indicate that households in Wajir were more likely to report such help (17\%) compared to their counterparts in Kibera (4\%). The Hunger Safety Net Program (HSNP), launched in 2008 in northern Kenya, provides cash transfers to poor households to improve the capacity of beneficiary households to meet essential needs such as paying for school fees, health care, or livestock feed. ${ }^{23}$ Results from the baseline survey shows that about a third (35\%) of the households in our study sample in Wajir were beneficiaries of this program. ${ }^{j}$

With regard to the employment status of parents, the majority of the parents in Wajir were not earning any cash to support the family, though fathers in Wajir were more likely to report earning cash for the family (17\%) compared with mothers (6\%). In Kibera, $65 \%$ of mothers reported working to earn cash for the family compared with $62 \%$ of the fathers in the sample. It is therefore not surprising that the majority of breadwinners in Wajir reported not losing their jobs in the past year (97\%), compared with 33\% of breadwinners who reported losing their jobs in Kibera. More than half of households in Kibera (56\%) and Wajir (52\%) reported that in the last one month, there was at least a day that the household went without food.

i We believe these numbers might be under-reported because respondents feared that it would make them ineligible for whatever program AGI-K might be offering.

jThe discrepancy between reporting of receiving household cash/in kind and receiving HSNP in Wajir is likely due to families not perceiving government aid as being provided by an "organization." 
With respect to savings, respondents were asked if the households had enough savings or an asset to sell in case of an emergency. Respondents were asked if these savings were equivalent to 1000,5000 or 10000 Kenyan shillings (KES). As seen in table 9, about 1 in 2 households in both Kibera and Wajir reported having savings or assets worth 1000 KES to use in case of an emergency. This proportion significantly drops to about a quarter of households (25\%) in both sites when asked if the household had $5000 \mathrm{KES}$, and further to $10 \%$ in Kibera and $13 \%$ in Wajir when asked if the household had savings or assets worth $10000 \mathrm{KES}$.

TABLE 9 Percent distribution of households' financial status, Kibera and Wajir, 2015

\begin{tabular}{|c|c|c|c|c|}
\hline \multirow[b]{2}{*}{ FINANCIAL STATUS } & \multicolumn{2}{|c|}{ KIBERA ( $(\mathrm{N}=2375)$} & \multicolumn{2}{|c|}{ WAJIR $\left(\mathrm{N}=1887^{*}\right)$} \\
\hline & $\%$ & $(\mathrm{~N})$ & $\%$ & $(\mathrm{~N})$ \\
\hline \multicolumn{5}{|c|}{$\begin{array}{l}\text { Household provided with cash/in kind support for daily needs by an } \\
\text { organization in last } 1 \text { year }\end{array}$} \\
\hline Yes & 3.87 & $(92)$ & 17.03 & $(322)$ \\
\hline No & 96.13 & $(2283)$ & 82.76 & $(1565)$ \\
\hline \multicolumn{5}{|c|}{ Is your household part of the Hunger Safety Net Program (HSNP)a } \\
\hline Yes & - & - & 34.96 & (661) \\
\hline No & - & - & 64.46 & $(1219)$ \\
\hline \multicolumn{5}{|c|}{ Mother earns cash to support family } \\
\hline Yes & 64.67 & $(1536)$ & 5.87 & $(111)$ \\
\hline No & 35.33 & (839) & 93.92 & $(1776)$ \\
\hline \multicolumn{5}{|c|}{ Father earns cash to support family } \\
\hline Yes & 62.32 & $(1480)$ & 16.66 & (315) \\
\hline No & 37.68 & (895) & 83.13 & $(1572)$ \\
\hline \multicolumn{5}{|c|}{ Household breadwinner(s) lost their job in the past year? } \\
\hline Yes & 32.88 & (781) & 2.54 & $(48)$ \\
\hline No & 67.12 & $(1594)$ & 97.25 & $(1839)$ \\
\hline \multicolumn{5}{|c|}{$\begin{array}{l}\text { In the past } 1 \text { month, was there a day household went without food } \\
\text { because there wasn't enough food in the household? }\end{array}$} \\
\hline Yes & 56.08 & $(1332)$ & 52.25 & $(988)$ \\
\hline No & 43.92 & $(1043)$ & 47.54 & (899) \\
\hline \multicolumn{5}{|c|}{ Does your household have : } \\
\hline \multicolumn{5}{|c|}{ Sufficient savings or assets to raise KES worth $1000 ?$} \\
\hline Yes & 54.82 & $(1302)$ & 47.49 & (898) \\
\hline No & 45.18 & $(1073)$ & 52.30 & (989) \\
\hline \multicolumn{5}{|c|}{ Sufficient savings or assets to raise KES worth $5000 ?$} \\
\hline Yes & 25.05 & $(595)$ & 24.75 & (468) \\
\hline No & 74.95 & $(1780)$ & 75.04 & (1419) \\
\hline \multicolumn{5}{|c|}{ Sufficient savings or assets to raise KES worth $10000 ?$} \\
\hline Yes & 9.68 & $(230)$ & 13.33 & (252) \\
\hline No & 90.32 & (2145) & 86.46 & (1635) \\
\hline
\end{tabular}

aProgram implemented only in Wajir.

*4 households with missing data.

\section{EDUCATION}

\section{School Attendance and Grade Attainment}

There is a wide range of research that has shown the benefits of education for girls, including delaying marriage and childbearing, positive effects on a woman's children, and economic benefits to a woman, her family, and her community. However, in addition, new thinking on education also posits that education alone is not enough to achieve "empowerment," and that 
girls need critical thinking skills as well as changes in their enabling environment. ${ }^{24}$ Therefore, not only are the educational attainment and school attendance rates important, but girls' outcomes on cognitive, literacy, and numeracy tests give a sense of general intelligence of younger adolescent girls in Kibera and Wajir at baseline.

In Kibera, almost all respondents (99\%) are currently attending school, with a mean age of starting school of 6.6. For girls ages $11-12$, the mean years of school completed is 4.9 , while the mean years of school completed of 13-15-year-old girls is greater at 6.2 years. The majority of girls in Kibera ages 11-12 (80\%) are at their expected grade level or ahead while $16 \%$ of this age group are one or two grades behind. Grade attainment rates are slightly lower for the 13-15-years-old girls, with $63 \%$ at their expected grade level or ahead and almost one-third (30\%) one to two grades behind.

TABLE 10 Percentage of girls who are attending school and their level of educational attainment, Kibera and Wajir, 2015

\begin{tabular}{|c|c|c|c|c|c|c|c|c|}
\hline & \multicolumn{4}{|c|}{ KIBERA } & \multicolumn{4}{|c|}{ WAJIR } \\
\hline & $\begin{array}{l}\text { AGES } \\
11-12\end{array}$ & $\begin{array}{l}\text { AGES } \\
13-14\end{array}$ & $(\mathrm{~N})^{*}$ & P-VALUE & $\begin{array}{l}\text { AGES } \\
11-12\end{array}$ & $\begin{array}{l}\text { AGES } \\
13-14\end{array}$ & $(\mathrm{~N})$ * & P-VALUE \\
\hline Currently attending school & & & & 0.00 & & & & 0.62 \\
\hline Yes & 99.83 & 98.00 & $(2367)$ & & 72.30 & 70.47 & (1537) & \\
\hline No & 0.17 & 1.92 & $(26)$ & & 3.85 & 3.87 & (83) & \\
\hline Never attended school & 0.00 & 0.08 & (1) & & 23.85 & $\begin{array}{c}25.65 \\
3.5\end{array}$ & $(530)$ & \\
\hline Mean years completed (SD) & $4.9(1.3)$ & $6.2(1.6)$ & $(2394)$ & 0.00 & $2.3(1.9)$ & $(2.7)$ & $(2150)$ & 0.00 \\
\hline Highest grade attainment & & & & 0.00 & & & & 0.00 \\
\hline No schooling/no grade completed & 0.00 & 0.16 & $(2)$ & & 25.94 & 26.39 & $(562)$ & \\
\hline Standard 1-3 & 11.43 & 6.09 & $(207)$ & & 44.02 & 18.43 & $(702)$ & \\
\hline Standard 4-8 & 88.57 & 91.35 & $(2155)$ & & 30.04 & 54.45 & (879) & \\
\hline Form 1-3 & 0.00 & 2.40 & (30) & & 0.00 & 0.73 & (7) & \\
\hline Grade for age & & & & 0.00 & & & & 0.10 \\
\hline At expected grade level or ahead & 79.58 & 62.50 & (1692) & & 21.51 & 21.26 & $(460)$ & \\
\hline 1 to 2 grades behind & 15.97 & 29.81 & $(555)$ & & 32.64 & 28.69 & $(664)$ & \\
\hline 3 or more grades behind & 4.45 & 7.69 & $(147)$ & & 45.86 & 50.05 & $(1026)$ & \\
\hline (N) & $(1146)$ & $(1248)$ & $(2394)$ & & (1195) & $(955)$ & $(2150)$ & \\
\hline
\end{tabular}

School attendance rates and grade attainment levels are much lower in Wajir. While the majority of girls are currently attending school in both age groups (72\% of $11-12$-year-olds; $70 \%$ of 13-14-year-olds), a significant proportion of girls have never been to school (24\% of $11-12$ year-olds and $26 \%$ of $13-14$-year-olds). The mean age of starting Standard 1 for girls in Wajir is 8.6. An average of $48 \%$ in both age groups are three or more grades behind in school and only $21 \%$ of girls in both age groups are at their expected grade level. 


\section{Literacy, Numeracy, and Cognitive Test Outcomes}

The survey respondents also completed numeracy, literacy, and cognitive assessments to gauge their skills in these areas. The literacy test assessed the girls' ability to completely read aloud two sentences in Swahili and two sentences in English. ${ }^{k}$ The preponderance of respondents in Kibera (93\%) were able to read both sentences in English. Younger adolescent girls in Kibera also had high levels of literacy in Swahili with $94 \%$ of respondents who were able to completely read the two Swahili sentences.

The girls were also given a numeracy test of 26 questions to assess their knowledge of mathematics including addition, subtraction, division, and multiplication. The numeracy test was developed by Uwezo, an East African education organization, and is based on the Kenyan Standard 2 level curriculum. ${ }^{25}$ Overall, in Kibera, girls scored in the 90th percentile or higher if they had attended school. The girls in both age groups who were in Standard 1 to 3 answered an average of $90 \%$ of the questions correctly. There was no difference across the two age groups among girls in Standard 4 to 8, with both age cohorts answering an average of $96 \%$ of numeracy questions correctly.

TABLE 11 Literacy, numeracy, and cognitive test outcomes, Kibera and Wajir, 2015

\begin{tabular}{|c|c|c|c|c|c|c|c|c|}
\hline & \multicolumn{4}{|c|}{ KIBERA } & \multicolumn{4}{|c|}{ WAJIR } \\
\hline & $\begin{array}{l}\text { AGES } \\
11-12\end{array}$ & $\begin{array}{l}\text { AGES } \\
13-14\end{array}$ & (N)* & P-VALUE & $\begin{array}{l}\text { AGES } \\
11-12\end{array}$ & $\begin{array}{l}\text { AGES } \\
13-14\end{array}$ & $(\mathrm{~N}) *$ & P-VALUE \\
\hline \multicolumn{9}{|l|}{ Literacy outcomes (\%) } \\
\hline Girls who can read English & 91.97 & 94.63 & (2235) & 0.01 & 27.78 & 44.61 & $(758)$ & 0.00 \\
\hline Girls who can read Swahili & 93.98 & 95.83 & (2273) & 0.04 & 34.48 & 48.90 & (879) & 0.00 \\
\hline \multicolumn{9}{|c|}{$\begin{array}{l}\text { Numeracy outcomes (Average \% } \\
\text { of questions answered correctly) }\end{array}$} \\
\hline No schooling & 0.00 & 80.70 & (2) & - & 9.40 & 11.80 & $(556)$ & 0.20 \\
\hline Standard 1-3 & 89.96 & 90.38 & (207) & 0.82 & 66.90 & 68.50 & $(700)$ & 0.55 \\
\hline Standard 4-8 & 95.58 & 95.52 & $(2140)$ & 0.83 & 87.51 & 90.55 & (877) & 0.00 \\
\hline Form 1-3 & 0.00 & 96.43 & $(28)$ & - & 0.00 & 98.90 & (7) & - \\
\hline \multicolumn{9}{|c|}{$\begin{array}{l}\text { Cognitive test outcomes (Average \% } \\
\text { of questions answered correctly) }\end{array}$} \\
\hline No schooling & - & 55.56 & (2) & - & 29.50 & 29.84 & $(556)$ & 0.84 \\
\hline Standard 1-3 & 44.40 & 49.85 & (207) & 0.03 & 38.68 & 37.99 & $(700)$ & 0.63 \\
\hline Standard 4-8 & 56.27 & 59.50 & $(2140)$ & 0.00 & 41.91 & 43.62 & $(877)$ & 0.15 \\
\hline Form 1-3 & - & 63.49 & $(28)$ & - & - & 41.27 & (7) & - \\
\hline$(\mathrm{N})$ & (1146) & (1248) & (2394) & & (1195) & (955) & $(2150)$ & \\
\hline
\end{tabular}

*Some of the total $\mathrm{N}$ might be inconsistent due to missing data.

A dash means that data are unavailable or cases equal zero in those cells.

In Kibera, a small percentage of girls in the sample had turned 15 by the time they were interviewed for the baseline survey.

\footnotetext{
k These sentences include the following: 1. Parents love their children. 2. Farming is hard work. These sentences were used in the Kenya DHS, page 32, http://dhsprogram.com/pubs/pdf/fr229/fr229.pdf.
} 
In addition, the respondents completed a Raven Progressive Matrices test, which is a nonverbal multiple-choice assessment of children's cognitive ability where the subject is asked to identify the missing element that completes a pattern.' The Raven tests are a test measure of one's ability to make sense out of confusing or complex data and the ability to perceive new patterns and relationships, with results typically following a bell curve pattern. ${ }^{9}$ The respondents answered questions derived from every other slide from Raven matrices $A A, A B, B B$, for a total of 18 slides. Among girls in Standard 4 to 8, the younger age group scored slightly less with an average of $56 \%$ of questions answered correctly on the cognitive test compared to an average of $60 \%$ correct answers among the older age group. The scores tend to increase as grade attainment increases, showing the effect of schooling on this test outcome.

In Wajir, the literacy, numeracy, and cognitive test scores were generally lower and may reflect the lack of education of younger adolescent girls. The differences in literacy scores between the two age groups were statistically significant, with $28 \%$ of $11-12$-year-olds and $45 \%$ of 13 14-year-olds being able to completely read two sentences in English. The proportions were slightly higher for Swahili literacy, with 35\% of 11-12-year-olds and 49\% of 13-14-year-olds who were able to read Swahili. The numeracy scores for girls in Wajir showed that girls who had been to school had higher scores than those with no schooling. The latter answered only $11 \%$ of the numeracy questions correctly on average. Girls in both age groups and in Standard 1 to 3 answered about $68 \%$ of the numeracy questions correctly. Girls in Standard 4 to 8 had higher numeracy scores, with $88 \%$ of questions answered correctly by the younger group and an average of $91 \%$ of questions answered correctly by the older group. Respondents in Wajir scored similarly on the Raven cognitive tests across age groups, with 11-12-year-olds in Standard 4 to 8 having an average of $42 \%$ of questions answered correctly on the test and an average of $44 \%$ correct answers for the older cohort.

Education rates in Kibera and Wajir show a stark difference for educational experiences of younger adolescent girls in Kenya, due to the vastly different socioeconomic levels, geographies, and available resources of the two sites. In Kibera, school attendance is almost universal but almost one-third of all girls (29.3\%) are one or more grades behind in school, which reflects a need to focus on grade advancement and improving expected grade-for-age rates among the girls in Kibera. As expected, the grade attainment and school attendance rates in rural Wajir are much lower. A quarter of the girls in Wajir had never attended school and almost half of all adolescent girls were three or more grades behind their expected grade level. The lower scores in literacy and numeracy outcomes also reflect the low learning outcomes in Wajir.

\section{Time Use}

Respondents reported time use gives an idea of the predominant activities in younger adolescent girls' lives and indicates potential social isolation if hours working at home are high. Younger adolescent girls in Kibera spend a majority of their day in school, with a mean report-

\footnotetext{
I Pearson Assessment. (2015). Raven's progressive matrices, available at http://www.pearsonclinical.co.uk/Psychology/AdultCognitionNeuropsychologyandLanguage/AdultGeneral Abilities/Ravens-Progressive-Matrices/Ravens-Progressive-Matrices.aspx, accessed July 20, 2015.
} 
ed 9.7 hours of school per day. Respondents reported spending around 1 hour per day on unpaid work at home, such as cooking and cleaning, and 1 hour per day on leisure time.

Girls in Wajir spend almost as much time doing unpaid work at home as they do going to school. The older girls spend significantly more hours per day (3.4) on unpaid household chores than their younger counterparts (3.1). Overall, girls spend only slightly more time at school, with an average of 3.8 hours per day.

TABLE 12 Average number of hours spent per weekday on various activities, mean (SD), Kibera and Wajir, 2015

\begin{tabular}{|c|c|c|c|c|c|c|c|c|}
\hline & \multicolumn{4}{|c|}{ KIBERA } & \multicolumn{4}{|c|}{ WAJIR } \\
\hline & $\begin{array}{l}\text { AGES } \\
11-12\end{array}$ & $\begin{array}{l}\text { AGES } \\
13-14\end{array}$ & $(\mathrm{~N})^{*}$ & P-VALUE & $\begin{array}{l}\text { AGES } \\
11-12\end{array}$ & $\begin{array}{l}\text { AGES } \\
13-14\end{array}$ & $(\mathrm{~N})^{*}$ & P-VALUE \\
\hline \multicolumn{9}{|l|}{$\begin{array}{l}\text { Mean number of hours per weekday } \\
\text { spent on the following activities: }\end{array}$} \\
\hline In school & $9.70(2.8)$ & $10.20(2.9)$ & (2393) & 0.00 & $3.67(3.5)$ & $3.98(4)$ & $(2147)$ & 0.18 \\
\hline $\begin{array}{l}\text { Unpaid work at home (e.g., cooking, } \\
\text { cleaning, washing clothes) }\end{array}$ & $0.96(1.2)$ & $1.02(1)$ & (2391) & 0.22 & $3.13(2.3)$ & $3.38(2.3)$ & (2150) & 0.03 \\
\hline $\begin{array}{l}\text { Unpaid work outside the home (e.g., } \\
\text { going to the market, fetching water) }\end{array}$ & $0.33(.7)$ & $0.37(.8)$ & $(2392)$ & 0.15 & $0.97(1.3)$ & $0.99(1.2)$ & (2150) & 0.63 \\
\hline Paid wage work & $0.03(.4)$ & $0.03(.4)$ & (2394) & 0.83 & $0.11(.6)$ & $0.09 .5)$ & (2150) & 0.32 \\
\hline Leisure time & $1.1(1.4)$ & $1.07(1.2)$ & (2392) & 0.91 & $1.33(1.8)$ & $1.26(1.6)$ & (2150) & 0.41 \\
\hline $\begin{array}{l}\text { Church/mosque/praying/duksi/ } \\
\text { madrasa }\end{array}$ & $0.33(1.1)$ & $0.37(1.2)$ & $(2393)$ & 0.32 & $0.81(1.5)$ & $0.68(1.3)$ & (2148) & 0.05 \\
\hline (N) & (1146) & (1248) & (2394) & & (1195) & (955) & (2150) & \\
\hline
\end{tabular}

*Some of the total $\mathrm{N}$ might be inconsistent due to missing data.

In Kibera, a small percentage of girls in the sample had turned 15 by the time they were interviewed for the baseline survey.

\section{WEALTH CREATION}

One of the goals of the wealth-creation intervention in AGI-K is to increase younger adolescent girls' savings and financial literacy, that is, their knowledge of how money is earned, managed, saved, invested, and spent, and to teach them to make budgets and savings plans and understand the benefits of both.

In Kibera, girls in the older cohort showed significantly higher financial literacy by correctly answering more questions related to budgeting, planning, and saving than girls in the younger cohort. On a ten-item scale, the younger girls had a mean score of 5.5 compared to the older girls (5.8). Just over one-quarter of younger adolescent girls in Kibera (27\%) had saved in the past six months. Of those who had saved, 93\% of girls in both groups had only informal savings, which includes saving in a home/piggy bank, with parents and friends, or with savings group/chama. Around 3\% of girls in both age groups had both formal and informal savings.

Financial literacy was lower overall in Wajir and had the same trend of older girls scoring higher on the ten-item scale with a 4.4 mean score for older girls and a 3.9 mean score among the younger girls. Savings practices in Wajir were almost nonexistent with only $11(0.1 \%)$ girls saving in the 6 months preceding the survey. 
TABLE 13 Financial literacy and savings, Kibera and Wajir, 2015

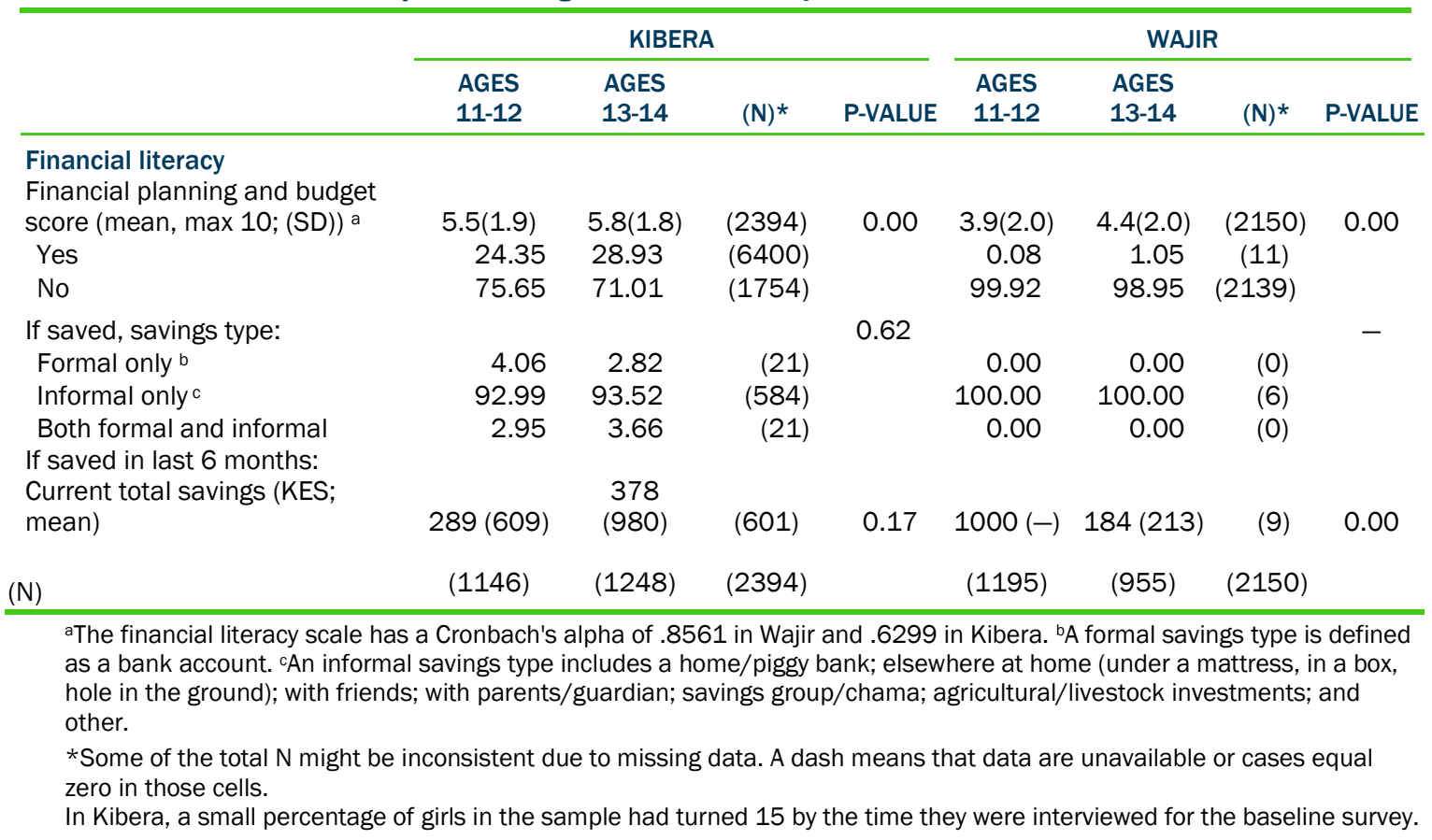

A small percentage of girls had ever worked for pay in cash or in kind in Kibera (8\%). Of those who had worked, half of the younger girls started working at age 11-12, showing they had just initiated working. The same trend is seen among the older girls, with almost half $(49 \%)$ having started work at age 13-15, showing a recent start to working for pay. The most common types of work for girls was washing dishes, braiding hair, and babysitting.

In Kibera, $41 \%$ of the younger girls and $45 \%$ of the older girls had spent money on their daily needs in the past year. Of those who had spent money, most girls received this money from their parents/guardians ( $48 \%$ of younger girls and $46 \%$ of older girls). Around $30 \%$ of girls in both age groups received this money from other relatives and 15\% of girls used money from their personal savings to buy items for their daily needs. In Wajir, only $1 \%$ of younger adolescent girls had ever worked for pay in cash or in kind. Only $1 \%$ of all respondents in Wajir had spent money on their daily needs in the past year.

Overall, the proportions of girls who save in Wajir and Kibera are low, especially formal ways of saving money such as in a bank account. The number of girls who are saving both formally and informally is expected to rise substantially once AGI-K interventions begin. 
TABLE 14 Work and expenses, Kibera and Wajir, 2015

\begin{tabular}{|c|c|c|c|c|c|c|c|c|}
\hline & \multicolumn{4}{|c|}{ KIBERA } & \multicolumn{4}{|c|}{ WAJIR } \\
\hline & $\begin{array}{l}\text { AGES } \\
11-12\end{array}$ & $\begin{array}{l}\text { AGES } \\
13-14\end{array}$ & $(\mathrm{~N})^{*}$ & P-VALUE & $\begin{array}{l}\text { AGES } \\
11-12\end{array}$ & $\begin{array}{l}\text { AGES } \\
13-14\end{array}$ & $(\mathrm{~N})^{*}$ & P-VALUE \\
\hline $\begin{array}{l}\text { Percentage of girls who have ever } \\
\text { worked for pay in cash or in kind } \\
\text { Among those who have worked for }\end{array}$ & 6.98 & 8.57 & $(187)$ & 0.15 & 0.50 & 1.78 & (23) & 0.00 \\
\hline pay: & & & & 0.00 & & & & 0.01 \\
\hline Began working at age $4-10$ & 46.25 & 19.63 & $(58)$ & & 100.00 & 29.41 & (11) & \\
\hline Began working at age 11-12 & 50.00 & 31.78 & (74) & & 0.00 & 0.00 & (0) & \\
\hline Began working at age $13-15$ & 0.00 & 48.60 & (52) & & 0.00 & 5.88 & (1) & \\
\hline Don't know/ don't remember & 3.75 & 0.00 & (3) & & 0.00 & 64.71 & (11) & \\
\hline $\begin{array}{l}\text { Percentage of girls who have spent } \\
\text { any money on their daily needs in the } \\
\text { last year }\end{array}$ & 40.92 & 44.87 & (1029) & 0.05 & 0.75 & 2.09 & (29) & 0.01 \\
\hline $\begin{array}{l}\text { Percentage of girls who got spending } \\
\text { money from the following: }\end{array}$ & & & & 0.05 & & & & 0.06 \\
\hline Parents/guardians & 48.40 & 45.97 & $(484)$ & & 77.78 & 55.00 & (18) & \\
\hline Other relatives/friends & 31.34 & 28.44 & (306) & & 22.22 & 0.00 & (2) & \\
\hline Male partner a & 0.00 & 0.36 & (2) & & 0.00 & 30.00 & (6) & \\
\hline Savings & 13.22 & 15.92 & (151) & & 0.00 & 5.00 & (1) & \\
\hline Jobs & 2.99 & 6.44 & (50) & & 0.00 & 0.00 & (0) & \\
\hline Other & 4.05 & 2.86 & (35) & & 0.00 & 10.00 & (2) & \\
\hline (N) & (1146) & (1248) & (2394) & & (1195) & $(955)$ & $(2150)$ & \\
\hline
\end{tabular}

aln Wajir, all the male partners were the girls' husbands.

In Kibera, a small percentage of the girls in the sample had turned 15 by the time they were interviewed for the baseline survey.

\section{HEALTH}

\section{Health Care Services}

This study will test the hypothesis that young adolescence is a critical time to intervene for girls in order to equip them with sexual and reproductive health knowledge and encourage healthseeking behaviors. The AGI-K theory of change posits that this will make them better prepared when exposed to the challenges of sexual initiation, negotiating condom use, preventing unintended pregnancies, and early marriage.

In Kibera, only $38 \%$ of girls had received health care in the six months preceding the survey. Most of the girls who did receive health care went for general health/sickness services (35\%) followed by pharmacy visits (7\%) (not shown). The main barriers to health care cited by girls in Kibera were needing money for treatment (41\%), not wanting to go alone (34\%), and concern that there may not be drugs available (28\%). Respondents were asked to rank their perceived health in the last year and last month on a scale of 0 to 10, with higher scores reflecting respondent's perception of being healthy and without illnesses. Self-reported health in the last year of girls was around 7.7 for both age groups in Kibera. There was a significant correlation between receiving health care and self-reported health scores. Girls who had sought out health care scored, on average, one point lower on the self-report scale, indicating poorer health. In general, adolescence is a time of good health and, because these girls are largely not sexually active, they also may not have a need for SRH services. Therefore, while health-care seeking 
might seem low, the correlation with lower self-reported health and receiving health care shows that girls may be seeking care when they need it.

Health care service utilization was lower among adolescent girls in Wajir with $17 \%$ of girls ages 11-12 and 20\% of girls ages 13-14 having received health care in the 6 months preceding the survey. Of the girls who sought health care, the main reasons they did were for general health/sickness (17\%) (not shown). The main barriers to care cited by adolescent girls in Wajir were needing money for treatment (48\%), distance to the health facility (39\%), and having to take transport to the health facility (37\%). Girls in Wajir had relatively high self-reported health averages of 8 for both age groups. Self-reported health is negatively correlated with receiving health care and girls who have received care will, on average, report 0.7 less on the scale than girls who did not receive care.

TABLE 15 Respondents' perceptions of their health in the past month and past year, and access to health care services, Kibera and Wajir, 2015

\begin{tabular}{|c|c|c|c|c|c|c|c|c|}
\hline & \multicolumn{4}{|c|}{ KIBERA } & \multicolumn{4}{|c|}{ WAJIR } \\
\hline & $\begin{array}{l}\text { AGES } \\
11-12\end{array}$ & $\begin{array}{l}\text { AGES } \\
13-14\end{array}$ & $(\mathrm{~N})^{*}$ & P-VALUE & $\begin{array}{l}\text { AGES } \\
11-12\end{array}$ & $\begin{array}{l}\text { AGES } \\
13-14\end{array}$ & $(\mathrm{~N})$ * & P-VALUE \\
\hline $\begin{array}{l}\text { Self-reported health in } \\
\text { last year a (mean, max }\end{array}$ & & 7.65 & & & & & & \\
\hline $\begin{array}{l}10 ;(S D)) \\
\text { Self-reported health in }\end{array}$ & $7.72(2.4)$ & $(2.2)$ & (2394) & 0.43 & $8.14(1.7)$ & $8.16(1.7)$ & $(2150)$ & 0.73 \\
\hline $\begin{array}{l}\text { last month a(mean, } \\
\max 10 ;(S D))\end{array}$ & $7.91(2.3)$ & $7.98(2.2)$ & (2394) & 0.44 & $8.23(1.7)$ & $8.27(1.6)$ & (2150) & 0.60 \\
\hline (percent) & & & & 0.48 & & & & 0.02 \\
\hline Yes & 38.74 & 37.34 & (910) & & 16.49 & 20.42 & (392) & \\
\hline No & 61.26 & 62.66 & $(1484)$ & & 83.51 & 79.58 & (1758) & \\
\hline (N) & (1146) & (1248) & $(2394)$ & & (1195) & (955) & $(2150)$ & \\
\hline
\end{tabular}

aRespondents were asked to rank their perceived health in the last month and in the last year on a scale of 0 to 10 , with higher scores reflecting respondents' perceptions of being healthier.

In Kibera, a small percentage of girls in the sample had turned 15 by the time they were interviewed for the baseline survey.

FIGURE 6 Percent distribution of perceived barriers to health care, Kibera and Wajir, 2015.

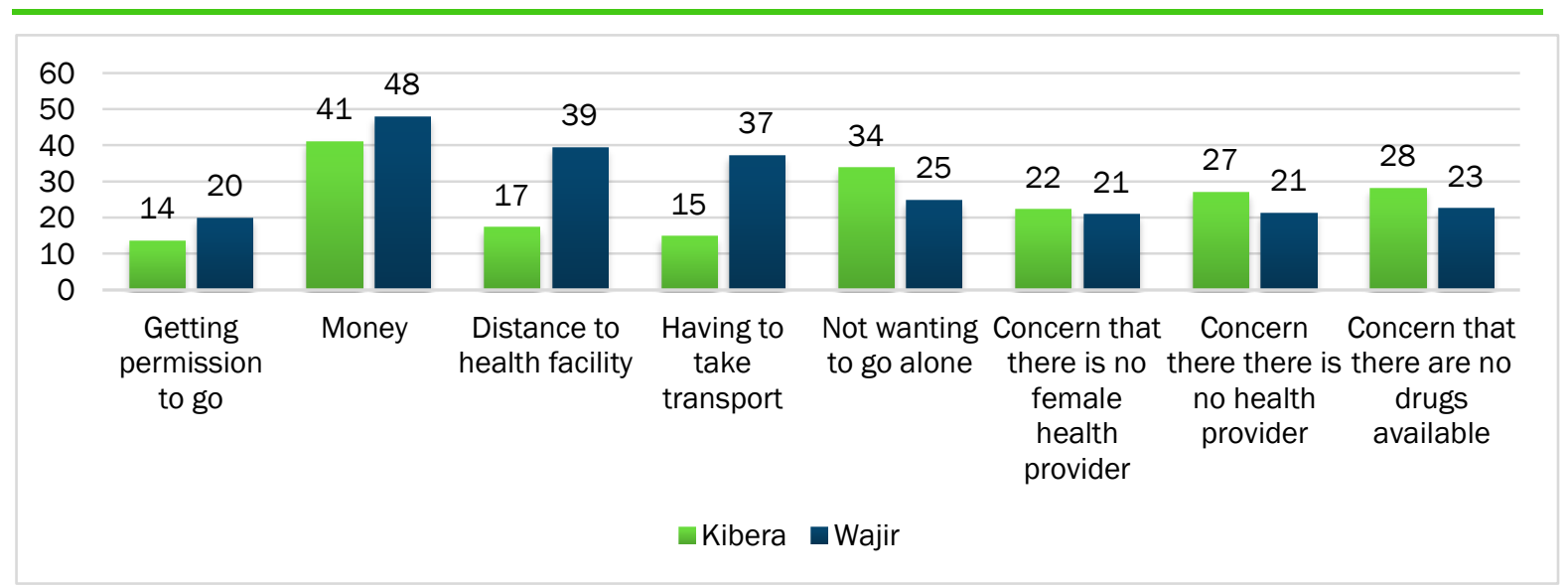




\section{Self-Efficacy and Social Networks}

The Safe Spaces groups in the AGI-K health intervention are intended to increase self-efficacy and strengthen peer networks and social support for younger adolescent girls in Kibera and Wajir. Social networks are essential for younger adolescent girls because they help reduce vulnerability and give girls a support system.

When girls were asked questions about their ability to handle tasks, accomplish goals, and overcome challenges, older girls in Kibera were significantly more likely to respond more positively than the younger cohort. On a six-item scale, the older girls had a self-efficacy score of 4.1 compared to their younger counterparts who reported 3.7 on average. Older girls also reported having significantly more friends ( 4.7 friends compared to 4 for younger girls). For both age groups, most friends were female.

Girls in Wajir had lower self-efficacy scores with an average of 2.1 for both age groups. Younger girls had a higher mean number of friends of 3.8 compared to 2.9 for older girls. Notably, $23 \%$ of younger girls and $18 \%$ of older girls reported having no friends. Girls who reported having no friends also scored much lower on the self-efficacy scale with a mean of 1.

TABLE 16 Self-efficacy and social networks, Kibera and Wajir, 2015

\begin{tabular}{|c|c|c|c|c|c|c|c|c|}
\hline & \multicolumn{4}{|c|}{ KIBERA } & \multicolumn{4}{|c|}{ WAJIR } \\
\hline & $\begin{array}{l}\text { AGES } \\
11-12\end{array}$ & $\begin{array}{l}\text { AGES } \\
13-14\end{array}$ & $(\mathrm{~N})$ * & P-VALUE & $\begin{array}{l}\text { AGES } \\
11-12\end{array}$ & $\begin{array}{l}\text { AGES } \\
13-14\end{array}$ & $(\mathrm{~N})^{*}$ & P-VALUE \\
\hline $\begin{array}{l}\text { Self-efficacy score } \\
\text { (mean, max 6; (SD)) a }\end{array}$ & $3.68(1.7)$ & $4.14(1.6)$ & 2394 & 0.00 & $2.12(2)$ & $2.17(2)$ & 2150 & 0.54 \\
\hline Mean number of friends & $4.03(5.8)$ & $4.71(7.6)$ & 2391 & 0.01 & $3.8(17)$ & $2.9(10)$ & 2150 & 0.18 \\
\hline Percent with no friends & 3.58 & 3.86 & 89 & & 23.18 & 17.70 & 446 & \\
\hline $\begin{array}{l}\text { Percent with } 1-4 \text { friends } \\
\text { Percent with } 5 \text { or more }\end{array}$ & 69.71 & 66.59 & 1628 & & 69.21 & 72.98 & 1524 & \\
\hline $\begin{array}{l}\text { friends } \\
\text { Mean number of male }\end{array}$ & 26.70 & 29.56 & 674 & 0.26 & 7.62 & 9.32 & 160 & 0.01 \\
\hline $\begin{array}{l}\text { friends } \\
\text { Mean number of female }\end{array}$ & $0.42(1.6)$ & $1.05(4.4)$ & 2394 & 0.00 & $1.0(8.6)$ & $0.42(5.2)$ & 2150 & 0.10 \\
\hline $\begin{array}{l}\text { friends } \\
\text { Could count on someone if } \\
\text { money was needed } \\
\text { urgently: }\end{array}$ & $3.61(4.9)$ & $3.98(7.1)$ & 2394 & 0.13 & $2.8(8.6)$ & $2.5(5.4)$ & 2150 & 0.33 \\
\hline Relative & 94.24 & 94.23 & 2256 & 0.99 & 84.10 & 83.35 & 1801 & 0.64 \\
\hline $\begin{array}{l}\text { Non-relative } \\
\text { Could count someone to } \\
\text { house you in case of an } \\
\text { emergency }\end{array}$ & 44.42 & 50.08 & 1134 & 0.01 & 9.29 & 9.95 & 206 & 0.61 \\
\hline Relative & 72.34 & 71.23 & 1718 & 0.55 & 32.05 & 34.14 & 709 & 0.31 \\
\hline Non-relative & 50.44 & 55.77 & 1274 & 0.01 & 12.30 & 11.73 & 259 & 0.69 \\
\hline (N) & (1146) & (1248) & (2394) & & (1195) & (955) & (2150) & \\
\hline
\end{tabular}

aSelf-efficacy scale has an alpha of .608 (Kibera) and .784 (Wajir). Higher scores reflect perceptions of greater selfefficacy.

*Some of the total $\mathrm{N}$ might be inconsistent due to missing data

In Kibera, a small percentage of girls in the sample had turned 15 by the time they were interviewed for the baseline survey. 


\section{Sexual and Reproductive Health Knowledge}

With respect to knowledge about HIV prevention and transmission, older girls in Kibera demonstrated more knowledge than their younger counterparts. On a 7-item scale assessing HIV knowledge, older girls had a mean score of 4.8 compared to 4.5 for younger girls.

HIV knowledge was quite low in Wajir, but this is probably due to the low HIV prevalence (0.9\%) in Northeastern Kenya. ${ }^{26}$ Older girls in Wajir demonstrated significantly greater knowledge with a mean score of 3.4 compared to younger girls who had a mean of 2.7 . Notably, $18 \%$ of these younger girls did not answer any questions correctly.

TABLE 17 Percentage of respondents who agree with selected statements about HIV/AIDS, Kibera and Wajir, 2015

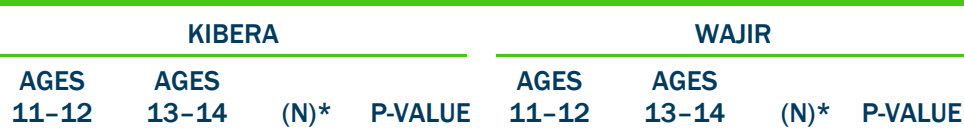

People can reduce their chances of getting the AIDS virus by having just one uninfected sex partner who has no other sex partners

People can reduce their chance of getting the AIDS virus by using a condom every time they have sex

People can reduce their chance of getting the AIDS virus by not having sexual intercourse at all

It is possible for a healthy-looking person to have the AIDS virus

The virus that causes AIDS can be transmitted from a mother to her baby during pregnancy

The virus that causes AIDS can be transmitted from a mother to her baby during delivery

The virus that causes AIDS can be transmitted from a mother to her baby by breastfeeding

Percentage who did not answer any questions on the scale correctly

HIV knowledge score (mean, $\max 7 ;(\mathrm{SD}))^{\text {a }}$

(N)

aHIV Knowledge scale has an alpha of .702 (Kibera) and .866 (Wajir).

* Some of the total $\mathrm{N}$ might be inconsistent due to missing data.

In Kibera, a small percentage of girls in the sample had turned 15 by the time they were interviewed for the baseline survey.

A majority (62\%) of 13-15-year-old girls know that there is a fertile period during the menstruation cycle, compared to just $40 \%$ of girls in the younger cohort. However, only $14 \%$ in both age groups were able to correctly identify when the fertile period occurs during the menstruation cycle. As expected, a significantly higher proportion of older girls (59\%) had started menstruation compared to just $14 \%$ of the 11-12-year-old girls. These significant differences in 
knowledge between age groups could be a reflection of a higher percentage of older girls that have started their periods and, therefore, have had more exposure to the topic.

Only 3\% of younger girls had started menstruation in Wajir compared to one-third of older girls. One in 10 older girls in Wajir did not know their age at menarche. It is not clear whether these girls had started menstruation due to the framing of the question, which asked about age of menarche rather than whether or not a girl had started menstruation. There was also an overall lack of sexual and reproductive health knowledge for all girls in Wajir. Less than $1 \%$ of girls in the younger age cohort in Wajir could identify a fertile period while $8 \%$ of older girls could.

TABLE 18 Percentage of girls who have begun menstruating and are knowledgeable about menstruation, Kibera and Wajir, 2015

\begin{tabular}{|c|c|c|c|c|c|c|c|c|}
\hline & \multicolumn{4}{|c|}{ KIBERA } & \multicolumn{4}{|c|}{ WAJIR } \\
\hline & $\begin{array}{l}\text { AGES } \\
11-12\end{array}$ & $\begin{array}{l}\text { AGES } \\
13-14\end{array}$ & $(\mathrm{~N})^{*}$ & P-VALUE & $\begin{array}{l}\text { AGES } \\
11-12\end{array}$ & $\begin{array}{l}\text { AGES } \\
13-14\end{array}$ & $(\mathrm{~N})^{*}$ & P-VALUE \\
\hline Menstruation started & & & & 0.00 & & & & 0.00 \\
\hline Yes & 13.53 & 58.89 & $(890)$ & & 3.18 & 33.93 & (362) & \\
\hline No & 86.13 & 40.30 & $(1490)$ & & 91.63 & 55.39 & $(1624)$ & \\
\hline Don't Know & 0.35 & 0.80 & (14) & & 5.19 & 10.68 & (164) & \\
\hline Age at menarche (mean; (SD)) & 11.6(.7) & $12.8(.9)$ & $(890)$ & 0.00 & $11.3(1.5)$ & $12.5(1.2)$ & $(362)$ & 0.00 \\
\hline cycle & 40.05 & 61.94 & (1232) & 0.00 & 0.75 & 8.27 & (88) & 0.00 \\
\hline $\begin{array}{l}\text { Percentage of girls who correct- } \\
\text { ly identify the middle of the }\end{array}$ & & & & & & & & \\
\hline cycle as the most fertile period & 14.16 & 14.62 & $(178)$ & 0.83 & 0.00 & 24.05 & (19) & 0.10 \\
\hline (N) & $(1146)$ & $(1248)$ & (2394) & & (1195) & (955) & $(2150)$ & \\
\hline
\end{tabular}

*Some of the total $\mathrm{N}$ might be inconsistent due to missing data.

In Kibera, a small percentage of the girls in the sample had turned 15 by the time they were interviewed for the baseline survey.

\section{Sexual Behaviorm}

Just $2 \%$ of younger adolescent girls in Kibera reported that they have ever had sex. Of those who reported ever having sex, the mean age of sexual initiation for 11-12 year olds was 9.6 compared to a mean age of 12 for the older cohort. Sixty-three percent of the younger girls reported that their first sex was unwanted compared to just 34\% of their older counterparts. While half of the girls in both age groups reported that their first partner was the same age or younger, around $13 \%$ of girls in both age groups reported that their first partner was 10 or more years older than them. Of the small subset of girls who were sexually experienced, consistent condom use was low (11\%) and one-quarter of older girls had ever used modern forms of contraception compared to just $6 \%$ of their younger counterparts. A majority of older girls (62\%) who had sex in Kibera had received an HIV test, which is significantly higher than the proportion of younger girls who had sex and report having an HIV test (31\%).

m For the sexual behavior section, data are not shown due to small numbers. 
In Wajir, results on sexual behavior are limited to girls who have ever been married or cohabitated with a boyfriend. Since the number of girls who had ever had sex was low $(n=21)$, the sexual behavior data are from a small subset of respondents and therefore not generalizable. Only 3 of the younger girls reported ever having sex compared to 18 (2\%) of the older girls. The mean of sexual initiation for the younger girls was 11.5, while the older girls have a mean age of 13 . Two of the younger girls did not want to have sex their first time, while 7 (39\%) of the 13-14-year-olds reported nonconsensual first sex. No girls in Wajir used a condom the first time they had sex and no girls had ever used any form of contraception. Only one girl had ever received an HIV test.

\section{VIOLENCE PREVENTION}

\section{Experiences of Violence}

In Kibera, an average of one-third (34\%) of adolescent girls had experienced at least one form of emotional, physical, or sexual violence. The experiences of physical violence, compared to emotional and sexual violence, were the most common among girls, with $23 \%$ of respondents having experienced physical violence. Older girls had significantly more experiences of sexual violence at $8 \%$ compared to their younger counterparts $(5 \%)$.

Respondents were also asked about situations when a husband was justified in beating his wife, to assess norms of violence in their communities. The situations included burning food, arguing with him, going out without telling him, neglecting the children, and refusing to have sexual intercourse. Neglecting the children had the highest percentages of agreement with $36 \%$ of younger girls and $41 \%$ of older girls believing a husband is justified in beating his wife if she neglects the children. There were significantly more girls in the older cohort (53\%) who agreed with at least one reason (out of 5 ) when a husband is justified in beating his wife, compared to $46 \%$ among younger girls.

TABLE 19 Percentage of respondents who have experienced violence, and attitudes about gender-based violence, Kibera and Wajir, 2015

\begin{tabular}{|c|c|c|c|c|c|c|c|c|}
\hline & \multicolumn{4}{|c|}{ KIBERA } & \multicolumn{4}{|c|}{ WAJIR } \\
\hline & $\begin{array}{c}\text { AGES } \\
11-12\end{array}$ & $\begin{array}{l}\text { AGES } \\
13-14\end{array}$ & $(\mathrm{~N})^{*}$ & P-VALUE & $\begin{array}{r}\text { AGES } \\
11-12\end{array}$ & $\begin{array}{r}\text { AGES } \\
13-14\end{array}$ & $(\mathrm{~N})^{*}$ & P-VALUE \\
\hline \multicolumn{9}{|l|}{ Ever experienced: } \\
\hline Emotional violence & 20.59 & 22.92 & (522) & 0.17 & 2.09 & 2.62 & (50) & 0.42 \\
\hline Physical violence & 23.91 & 22.68 & (557) & 0.48 & 2.43 & 2.30 & (51) & 0.85 \\
\hline Sexual violence & 4.62 & 7.45 & (146) & 0.00 & 0.59 & 0.31 & (10) & 0.36 \\
\hline $\begin{array}{l}\text { Any form of emotional, physi- } \\
\text { cal, sexual violence }\end{array}$ & 32.55 & 34.86 & $(808)$ & 0.23 & 3.77 & 3.46 & (78) & 0.70 \\
\hline \multicolumn{9}{|l|}{$\begin{array}{l}\text { A husband is justified in hitting } \\
\text { or beating his wife if she: }\end{array}$} \\
\hline Goes out without telling him & 11.17 & 12.98 & $(290)$ & 0.18 & 36.65 & 35.60 & $(778)$ & 0.61 \\
\hline Neglects the children & 36.21 & 40.71 & (923) & 0.02 & 38.16 & 40.52 & $(843)$ & 0.26 \\
\hline Argues with him & 21.55 & 24.92 & (558) & 0.05 & 39.16 & 38.43 & $(835)$ & 0.73 \\
\hline $\begin{array}{l}\text { Refuses to have sexual inter- } \\
\text { course with him }\end{array}$ & 6.28 & 5.37 & (139) & 0.34 & 26.44 & 25.86 & $(563)$ & 0.76 \\
\hline Burns the food & 9.08 & 9.05 & $(217)$ & 0.99 & 20.17 & 18.32 & $(416)$ & 0.28 \\
\hline $\begin{array}{l}\text { Percentage who agree with at } \\
\text { least one specified reason }\end{array}$ & 46.42 & 52.56 & (1188) & 0.00 & 50.54 & 52.04 & (1101) & 0.49 \\
\hline (N) & (1146) & (1248) & (2394) & & (1195) & (955) & (2150) & \\
\hline
\end{tabular}


Experiences of violence were lower for girls in Wajir, with just 4\% of all girls reporting experience with any form of emotional, physical, or sexual violence. Low reports of violence may reflect the sensitivities surrounding violence. Almost $60 \%$ of households in Wajir agreed that if a girl is raped, the matter should be settled between the girl's family and the man's family (not shown). However, when asked about norms of violence and when a husband is justified in beating his wife, over half of girls (51\%) agreed with at least one specified reason as a justification of abuse.

\section{Perceptions of Safety}

While the majority of girls (78\%) in Kibera reported that they felt safe walking around their communities during the day, a higher percentage of girls (90\%) in both age groups did not feel safe walking around at night in their communities. In addition, a high proportion of girls (71\%) reported that, in their everyday life, they were scared of being raped.

In Wajir, almost 3 in 4 young adolescent girls (73\%) feel safe walking around during the day and $58 \%$ feel safe walking after dark. Almost one-third (32\%) of girls in both age groups in Wajir reported that they feel scared they will be raped and $13 \%$ of the respondents said a boy or man had touched them indecently in the past six months.

TABLE 20 Percentage of respondents who agree with selected statements about neighborhood/community safety, Kibera and Wajir, 2015

\begin{tabular}{|c|c|c|c|c|c|c|c|c|}
\hline & \multicolumn{4}{|c|}{ KIBERA } & \multicolumn{4}{|c|}{ WAJIR } \\
\hline & $\begin{array}{l}\text { AGES } \\
11-12\end{array}$ & $\begin{array}{c}\text { AGES } \\
13-14\end{array}$ & $(\mathrm{~N})$ * & P-VALUE & $\begin{array}{l}\text { AGES } \\
11-12\end{array}$ & $\begin{array}{l}\text { AGES } \\
13-14\end{array}$ & $(\mathrm{~N})^{*}$ & P-VALUE \\
\hline $\begin{array}{l}\text { I feel safe walking around my neigh- } \\
\text { borhood/community during the day }\end{array}$ & & & & 0.80 & & & & 0.79 \\
\hline Agree & 79.96 & 76.52 & (1837) & & 73.31 & 73.82 & (1581) & \\
\hline Disagree & 23.04 & 23.48 & $(557)$ & & 26.69 & 26.18 & $(569)$ & \\
\hline $\begin{array}{l}\text { I feel safe walking around my neigh- } \\
\text { borhood/community after dark }\end{array}$ & & & & 0.54 & & & & 0.12 \\
\hline Agree & 10.12 & 10.90 & $(252)$ & & 56.65 & 60.00 & (1250) & \\
\hline Disagree & 89.88 & 89.10 & $(2142)$ & & 43.35 & 40.00 & $(900)$ & \\
\hline $\begin{array}{l}\text { I have been robbed in the past six } \\
\text { months in my neighborhood/ } \\
\text { community }\end{array}$ & & & & 0.99 & & & & 0.41 \\
\hline Agree & 11.78 & 11.78 & $(282)$ & & 11.80 & 12.98 & (265) & \\
\hline Disagree & 88.22 & 88.22 & $(2112)$ & & 88.20 & 87.02 & (1885) & \\
\hline $\begin{array}{l}\text { I have been touched indecently by a } \\
\text { boy or man in the past six months }\end{array}$ & & & & 0.18 & & & & 0.08 \\
\hline Agree & 5.41 & 6.73 & (146) & & 13.97 & 11.41 & (276) & \\
\hline Disagree & 94.59 & 93.27 & $(2248)$ & & 86.03 & 88.59 & (1874) & \\
\hline $\begin{array}{l}\text { Sometimes, in my everyday life, I feel } \\
\text { scared that I will be raped }\end{array}$ & & & & 0.01 & & & & 0.86 \\
\hline Agree & 72.86 & 67.55 & (1678) & & 31.80 & 32.15 & $(687)$ & \\
\hline Disagree & 27.14 & 32.45 & $(716)$ & & 68.20 & 67.85 & (1463) & \\
\hline $\begin{array}{l}\text { I have permission to travel to youth } \\
\text { group/girls group: }\end{array}$ & & & & 0.29 & & & & 0.20 \\
\hline On my own & 37.43 & 40.22 & (931) & & 8.43 & 10.55 & (202) & \\
\hline If someone accompanies me & 11.78 & 11.38 & $(277)$ & & 2.84 & 2.40 & (57) & \\
\hline Not allowed to go alone & 11.69 & 9.62 & (254) & & 16.86 & 14.63 & (342) & \\
\hline Never go to youth group/girls group & 39.09 & 38.78 & $(932)$ & & 71.81 & 72.41 & (1554) & \\
\hline (N) & (1146) & $(1248)$ & $(2394)$ & & $(1195)$ & $(955)$ & $(2150)$ & \\
\hline
\end{tabular}

*Some of the total $\mathrm{N}$ might be inconsistent due to missing data.

In Kibera, a small percentage of the girls in the sample had turned 15 by the time they were interviewed for the baseline survey. 


\section{GENDER ATTITUDES}

Adolescent girls in Kibera generally exhibit attitudes that promote gender equality. On average, the majority of adolescent girls (89\%) agreed with the statement "It is as important for girls to complete secondary school as it is for boys." Over three-quarters of survey respondents (77\%) agreed that girls are as intelligent as boys.

The attitudes surrounding gender equality differed in Wajir, with $31 \%$ of younger girls and $28 \%$ of older girls agreeing that if a family cannot afford to send children to school, it is better to send boys than girls. Two-thirds of girls (67\%) agreed that girls are as intelligent as boys and $64 \%$ disagree that the husband's opinion matters more with respect to deciding on the number of children to have, showing moderate attitudes of gender equality among younger adolescent girls in Wajir.

TABLE 21 Percentage of respondents who agree with selected statements about gender equality, Kibera and Wajir, 2015

\begin{tabular}{|c|c|c|c|c|c|c|c|c|}
\hline & \multicolumn{4}{|c|}{ KIBERA } & \multicolumn{4}{|c|}{ WAJIR } \\
\hline & $\begin{array}{c}\text { AGES } \\
11-12\end{array}$ & $\begin{array}{c}\text { AGES } \\
13-14\end{array}$ & $(\mathrm{~N}) *$ & P-VALUE & $\begin{array}{l}\text { AGES } \\
11-12\end{array}$ & $\begin{array}{l}\text { AGES } \\
13-14\end{array}$ & $(\mathrm{~N})^{*}$ & P-VALUE \\
\hline \multicolumn{9}{|l|}{$\begin{array}{l}\text { It is as important for girls to com- } \\
\text { plete secondary school as it is for }\end{array}$} \\
\hline boys & & & & 0.21 & & & & 0.05 \\
\hline Agree & 88.31 & 89.90 & (2134) & & 71.88 & 75.71 & $(1582)$ & \\
\hline Disagree & 11.69 & 10.10 & $(260)$ & & 28.12 & 24.29 & $(568)$ & \\
\hline \multicolumn{9}{|l|}{$\begin{array}{l}\text { When a family cannot afford to } \\
\text { send all children to school, it is }\end{array}$} \\
\hline better to send boys than girls & & & & 0.20 & & & & 0.10 \\
\hline Agree & 7.94 & 6.57 & $(173)$ & & 30.88 & 27.64 & $(633)$ & \\
\hline Disagree & 92.06 & 93.43 & $(2221)$ & & 69.12 & 72.36 & (1517) & \\
\hline \multicolumn{9}{|c|}{$\begin{array}{l}\text { When a husband and wife disa- } \\
\text { gree about the number of children } \\
\text { to have, the husband's opinion }\end{array}$} \\
\hline matters more & & & & 0.75 & & & & 0.17 \\
\hline Agree & 22.34 & 21.79 & $(528)$ & & 37.07 & 34.24 & $(770)$ & \\
\hline Disagree & 77.66 & 78.21 & $(1866)$ & & 62.93 & 65.76 & $(1380)$ & \\
\hline $\begin{array}{l}\text { A 16-year-old girl should get ma } \\
\text { ried when she finds an appropr } \\
\text { ate partner, even if she is still i }\end{array}$ & & & & & & & & \\
\hline school & & & & 0.18 & & & & 0.57 \\
\hline Agree & 2.27 & 1.52 & $(45)$ & & 21.59 & 22.62 & $(474)$ & \\
\hline Disagree & 97.73 & 98.48 & $(2349)$ & & 78.41 & 77.38 & $(1676)$ & \\
\hline Girls are as intelligent as boys & & & & 0.14 & & & & 0.19 \\
\hline Agree & 75.31 & 77.88 & $(1835)$ & & 65.77 & 68.48 & $(1440)$ & \\
\hline Disagree & 24.69 & 22.12 & $(559)$ & & 34.23 & 31.52 & $(710)$ & \\
\hline$(\mathrm{N})$ & $(1146)$ & (1248) & (2394) & & (1195) & (955) & $(2150)$ & \\
\hline
\end{tabular}

*Some of the total $\mathrm{N}$ might be inconsistent due to missing data.

In Kibera, a small percentage of girls in the sample had turned 15 by the time they were interviewed for the baseline survey. 


\section{EARLY MARRIAGE, CHILDBEARING, AND FEMALE GENITAL MUTILATION}

Marriage and childbearing rates were low for younger adolescent girls in Kibera with less than $1 \%$ of girls reporting having ever been married or giving birth. The rate of early marriage was slightly higher in Wajir with .25\% of younger girls and $2 \%$ of older girls having ever been married. Only 2 girls in the older cohort reported that they had ever given birth, which suggests that early childbearing rates are also low.

The majority of girls in Kibera had heard of female genital mutilation (FGM) (69\% of younger girls and $79 \%$ of older girls), while only $2 \%$ of girls in both age groups had been circumcised. Of those who had been circumcised, most were circumcised between the ages of 6 and 9 years old (50\%). The majority of girls who had been circumcised in Kibera belonged to the Kisii ethnicity group ( $85 \%$ ), followed by Borana (9\%) (not shown). A majority of girls (64\%) in Kibera saw no benefits of female circumcision and $97 \%$ of girls in both age groups did not intend to have their daughter circumcised, showing behavioral intent to discontinue the practice of FGM.

In Wajir, female circumcision is a widespread and commonly accepted cultural practice and therefore the attitudes and behaviors surrounding female circumcision in Wajir are strikingly contrasted to those of girls in Kibera. Almost all girls (99\%) had been circumcised in both age groups. Of those who were circumcised, most girls (54\%) were 6-9 years old when it happened. The main benefits of female circumcision that girls from Wajir cited were religious approval (61\%) and cleanliness/hygiene (33\%). The preponderance of respondents in Wajir (87\%) intended to have their daughter circumcised and $86 \%$ of younger adolescent girls thought that the practice of FGM should be continued.

TABLE 22 Percentage of girls who have married and given birth at an early age, Kibera and Wajir, 2015

\begin{tabular}{|c|c|c|c|c|c|c|c|c|}
\hline & \multicolumn{4}{|c|}{ KIBERA } & \multicolumn{4}{|c|}{ WAJIR } \\
\hline & $\begin{array}{c}\text { AGES } \\
11-12\end{array}$ & $\begin{array}{c}\text { AGES } \\
13-14\end{array}$ & $(\mathrm{~N})^{*}$ & $\begin{array}{c}\text { P- } \\
\text { VALUE }\end{array}$ & $\begin{array}{c}\text { AGES } \\
11-12\end{array}$ & $\begin{array}{c}\text { AGES } \\
13-14\end{array}$ & $(\mathrm{~N})^{*}$ & $\begin{array}{c}\text { P- } \\
\text { VALUE }\end{array}$ \\
\hline \multicolumn{9}{|l|}{ Early marriage } \\
\hline $\begin{array}{l}\text { Ever married } \\
\text { Yes } \\
\text { No }\end{array}$ & $\begin{array}{r}0.00 \\
100.0 \\
0\end{array}$ & $\begin{array}{r}0.32 \\
99.6 \\
8\end{array}$ & $\begin{array}{r}(4) \\
(2390)\end{array}$ & 0.06 & $\begin{array}{r}0.25 \\
99.75\end{array}$ & $\begin{array}{r}2.09 \\
97.91\end{array}$ & $\begin{array}{r}(23) \\
(212 \\
7)\end{array}$ & 0.00 \\
\hline \multicolumn{9}{|l|}{ Early childbearing } \\
\hline $\begin{array}{l}\text { Ever given birth } \\
\text { Yes } \\
\text { No }\end{array}$ & $\begin{array}{r}0.00 \\
100.0 \\
0\end{array}$ & $\begin{array}{r}0.16 \\
99.8 \\
4\end{array}$ & $\begin{array}{r}(2) \\
(2392)\end{array}$ & 0.18 & $\begin{array}{r}0.00 \\
100.00\end{array}$ & $\begin{array}{r}0.21 \\
99.79\end{array}$ & $\begin{array}{r}(2) \\
(214 \\
8)\end{array}$ & 0.11 \\
\hline (N) & $(1146)$ & $\begin{array}{r}(124 \\
8)\end{array}$ & (2394) & & (1195) & $(955)$ & $(2150)$ & \\
\hline
\end{tabular}

*Some of the total $\mathrm{N}$ might be inconsistent due to missing data.

In Kibera, a small percentage of girls in the sample had turned 15 by the time they were interviewed for the baseline survey. 
TABLE 23 Percentage of girls who have undergone female genital mutilation/circumcision and attitudes about the procedure, Kibera and Wajir, 2015

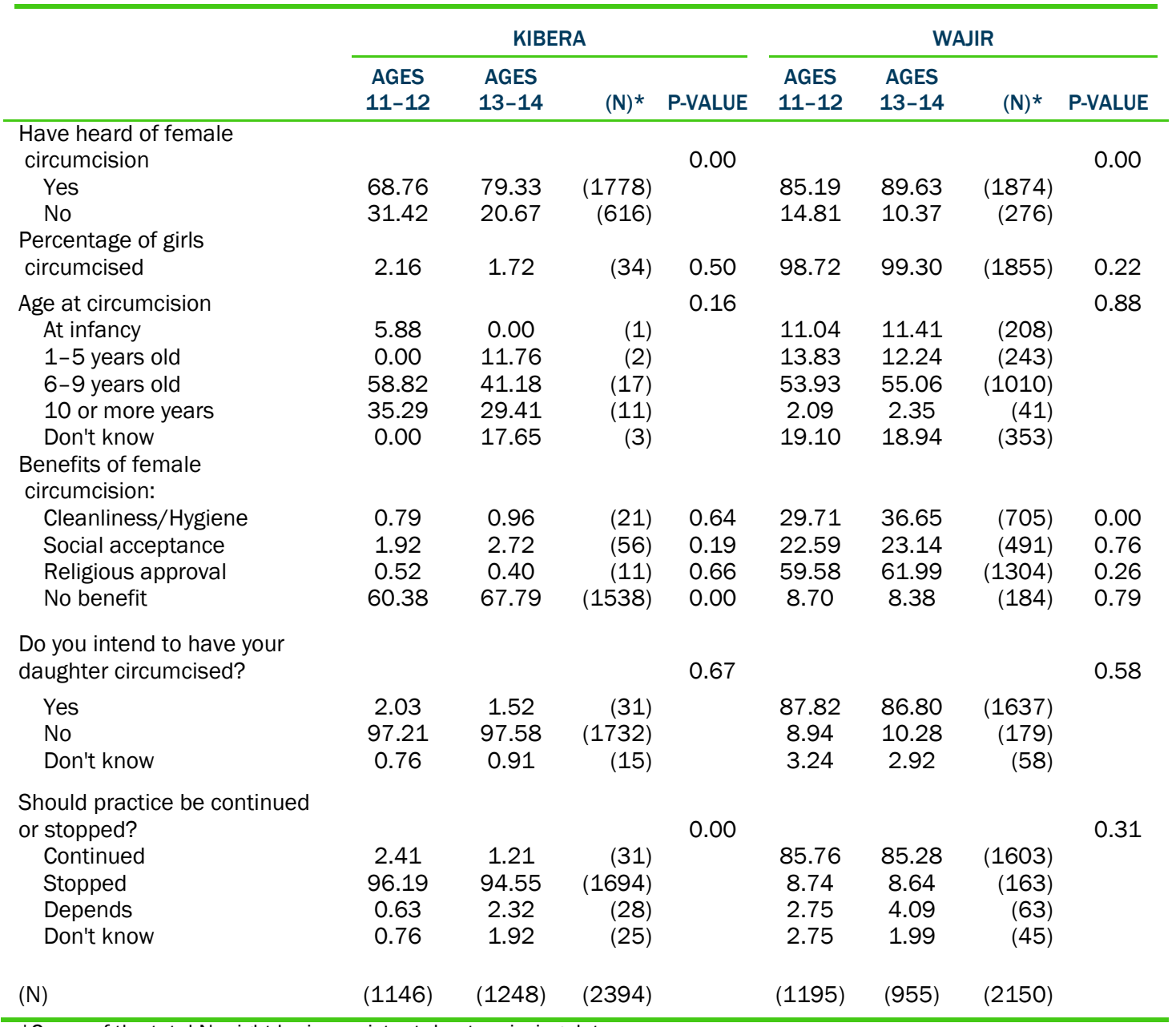

*Some of the total $\mathrm{N}$ might be inconsistent due to missing data.

In Kibera, a small percentage of girls in the sample had turned 15 by the time they were interviewed for the baseline survey.

\section{COMPARISON BETWEEN STUDY ARMS}

As described in the Inception Report, randomization was employed to achieve equal baseline balance on observed and unobserved characteristics of girls across the different study arms. Randomization was at the individual level in Kibera and at the cluster level in Wajir; consequently, the latter has many fewer randomized units (80 clusters in total). In Table 24 we confirm that there is good balance across the arms among observable characteristics related to each of the intervention domains, with few statistically significant differences across arms in both sites, though more occurring in Wajir consistent with the fewer randomization units. Impact analyses will include difference-in-difference approaches to control for the initial differences across arms on these or other characteristics. 
TABLE 24 Balance across research arms on selected girl characteristics, Kibera and Wajir, 2015

\begin{tabular}{|c|c|c|c|c|c|c|c|c|}
\hline & \multicolumn{4}{|c|}{ KIBERA } & \multicolumn{4}{|c|}{ WAJIR } \\
\hline & $\mathrm{v}$ & VE & VEH & VEHW & $\mathrm{v}$ & VE & VEH & VEHW \\
\hline & (1) & (2) & (3) & (4) & (1) & (2) & (3) & (4) \\
\hline \multirow[t]{2}{*}{ Age } & 12.66 & 12.63 & 12.72 & 12.63 & 12.44 & 12.47 & 12.31 & 12.37 \\
\hline & $(1.17)$ & $(1.18)$ & $(1.16)$ & $(1.14)$ & $(1.10)$ & (1.09) & $(1.06)$ & $(1.12)$ \\
\hline Currently attend school & 99.33 & 99.16 & $98.03^{*}$ & 98.99 & 77.56 & $66.06^{*}$ & 73.56 & 69.33 \\
\hline \multirow{2}{*}{$\begin{array}{l}\text { Age started school } \\
\text { (mean; (SD)) }\end{array}$} & 6.64 & 6.62 & 6.66 & 661 & & & & 26 \\
\hline & $\begin{array}{l}6.64 \\
(0.99)\end{array}$ & $\begin{array}{l}0.02 \\
(1.04)\end{array}$ & $\begin{array}{l}0.06 \\
(1.00)\end{array}$ & $\begin{array}{l}0.61 \\
(1.01)\end{array}$ & $\begin{array}{l}8.55 \\
(1.78)\end{array}$ & $\begin{array}{l}8.1 \perp \\
(1.71)\end{array}$ & $\begin{array}{l}8.58 \\
(1.67)\end{array}$ & $\begin{array}{l}8.06 \\
(1.74)\end{array}$ \\
\hline \multirow[t]{2}{*}{ Highest grade attainment } & 5.55 & 5.49 & 5.59 & 5.50 & 3.03 & 2.80 & 2.92 & 2.70 \\
\hline & $(1.66)$ & $(1.63)$ & $(1.57)$ & $(1.62)$ & $(2.31)$ & $(2.52)$ & $(2.39)$ & $(2.32)$ \\
\hline \multirow{6}{*}{$\begin{array}{l}\text { Literacy: Read English } \\
\text { Numeracy test: Percent- } \\
\text { age answered correctly } \\
\text { (\%) } \\
\text { Cognitive test: Percent- } \\
\text { age answered correctly } \\
\text { (\%) } \\
\text { Financial literacy (mean; } \\
\text { (SD)) }\end{array}$} & 92.63 & 94.28 & 92.46 & 94.10 & 38.78 & 31.95 & 37.62 & 33.03 \\
\hline & 24.73 & 24.83 & 24.68 & 24.63 & 67.39 & $58.68 *$ & 61.13 & 59.97 \\
\hline & & & & & & & & \\
\hline & 56.63 & 57.79 & 56.92 & 56.82 & 39.32 & 37.51 & 36.29 & 39.04 \\
\hline & 5.69 & 5.65 & 5.65 & 5.76 & 4.38 & 4.10 & 4.01 & 4.03 \\
\hline & $(1.90)$ & $(1.91)$ & $(1.93)$ & $(1.86)$ & $(1.98)$ & $(2.12)$ & $(2.00)$ & $(1.97)$ \\
\hline \multirow{4}{*}{$\begin{array}{l}\text { Saved money in last } 6 \\
\text { months (\%) } \\
\text { Self-reported health in } \\
\text { last year (mean; (SD)) }\end{array}$} & 27.14 & 25.08 & 26.39 & 28.33 & 0.59 & 0.36 & 0.37 & 0.73 \\
\hline & & & & & & & & \\
\hline & 7.58 & 7.61 & 7.76 & 7.78 & 8.05 & 8.27 & 8.15 & 8.12 \\
\hline & $(2.29)$ & $(2.30)$ & $(2.29)$ & $(2.23)$ & $(1.71)$ & $(1.63)$ & $(1.60)$ & $(1.84)$ \\
\hline \multirow[t]{2}{*}{$\begin{array}{l}\text { Self-efficacy score (mean; } \\
\text { (SD)) }\end{array}$} & 3.82 & 3.99 & 3.90 & 3.97 & 2.32 & 2.31 & 2.23 & $1.73 *$ \\
\hline & $(1.72)$ & $(1.57)$ & $(1.60)$ & $(1.58)$ & $(2.02)$ & (1.91) & $(1.94)$ & $(2.01)$ \\
\hline \multirow[t]{2}{*}{ HIV knowledge score } & 4.58 & 4.71 & 4.57 & 4.65 & 3.32 & 3.19 & 3.03 & $2.84 *$ \\
\hline & $(1.60)$ & $(1.53)$ & $(1.61)$ & $(1.53)$ & $(2.00)$ & $(1.90)$ & $(2.03)$ & $(1.81)$ \\
\hline Started menstruation (\%) & 36.99 & 38.18 & 37.75 & 36.66 & 19.27 & 19.92 & 16.06 & 17.70 \\
\hline Ever had sex (\%) & 2.51 & 1.68 & 2.13 & 2.70 & 2.36 & 1.08 & 1.12 & 2.90 \\
\hline Ever married (\%) & 0.17 & 0.00 & 0.16 & 0.34 & 1.38 & 0.72 & 0.74 & 1.45 \\
\hline
\end{tabular}

Note: Standard deviations in parentheses.

$\mathrm{V}=$ Violence Prevention Only, $\mathrm{E}=$ Education, $\mathrm{H}=$ Health, and $\mathrm{W}=$ Wealth Creation.

* indicates the arm is significantly different from column (1) Violence prevention only at $p<0.05$.

See text and previous tables for further details on the items. 


\section{Key Findings and Implications}

Very young adolescents growing up in marginalized and resource-constrained settings face considerable challenges and risks that affect their overall well-being. Intervening at a young age may have positive impacts including delaying sexual initiation, marriage, pregnancy (early and unintended), and improving learning outcomes. Baseline results from Kibera and Wajir suggest that although young adolescents face a myriad of challenges, the majority have not engaged in risk behaviors associated with poor sexual and reproductive health outcomes. Intervening in the different sectors (education, wealth, health, and violence prevention) therefore has the potential to delay or prevent negative outcomes that have not yet set in, as adolescents make the transition to adulthood in resource-constrained settings.

Overall, there were stark differences between Kibera (urban slum) and Wajir (rural area) in all four sectors. The differences between Nairobi and Wajir justify the importance of looking at these as sub-studies, as delineated in the Methodology section.

\section{EDUCATION}

One in four girls in Wajir had never attended school compared to less than $1 \%$ of girls in Kibera. This finding could partly explain the low literacy and numeracy scores in Wajir. Similarly, about a quarter of the girls in Wajir were in the expected class relative to their age, compared to $71 \%$ of girls in Kibera. However, in light of differences between younger versus older adolescents in grade-for-age, progression through grades might also be poor in Kibera. Findings suggest that girls in Wajir enroll in schools at a later age, compared with their counterparts in Kibera. Results from Wajir confirm findings from the needs assessment conducted by Save the Children, which showed that schooling for girls was often not made a priority, due in part to the heavy burden of household chores and to the low value that parents placed on educating girl children.

For Kibera, though, there is nearly universal school attendance. It is worth noting that a high proportion of girls in Kibera, as in other slums, attend informal schools. A study on quality and access to education in urban settlements in Kenya showed that about $47 \%$ of primary school children in informal settlements in Kenya attended nongovernment schools, with this proportion reaching $63 \%$ in Nairobi's informal settlements. ${ }^{27}$

In general, the results highlight the distinct disparities between regions in terms of access to schooling, with many girls not in school or behind in school in Wajir. Since the majority of girls in Kibera are attending school, the primary focus is in keeping them there so they can complete primary school and transition to secondary. As described in the AGI-K Theory of Change, increased schooling is expected to contribute toward delaying the age of marriage for girls in Wajir and the age of pregnancy for girls in Kibera. The Conditional Cash Transfer (CCT) intervention within the AGI-K program is expected to improve school attendance in Wajir by reducing the cost burden on families (through direct pay of expenses to schools) and acting as a monetary incentive to enroll and keep girls in schools (through monetary benefits to the households). In Kibera, where many girls are already in school, the CCT has the potential to 
improve grade progression by reducing school drop-out and grade repetition. In addition, as approximately half of the sample is in classes 7 and 8 , the CCT will likely improve the transition to secondary school over the two-year intervention period.

\section{WEALTH CREATION}

Overall, girls had low levels of financial literacy and savings. Although over $40 \%$ of girls in Kibera had access to cash, which they spent on their daily needs in the previous year, fewer than 30\% had any savings. Literature shows that economic strengthening through savings and financial literacy education can reduce girls' vulnerabilities (such as survival sex) and expand opportunities (such as vocational training). ${ }^{8}$ For example, studies in Kenya and Uganda show that girls who received financial education together with health education were not only likely to report saving money in the last six months and to have a budget, but also more likely to report improved reproductive health knowledge. ${ }^{8}$ Overall, the low levels observed in the baseline results suggest a critical need for the AGI-K wealth creation interventions, which will build girls' economic and social well-being by equipping them with money management skills and teaching them to save at a young age.

\section{HEALTH}

Overall, there were low levels of sexual activity among study participants, with only $2 \%$ of girls in both Kibera and Wajir having already initiated sex (all sexually active girls in Wajir were married). These low levels of sexual initiation at baseline mean that more girls stand to benefit from the interventions to delay sexual initiation. These data may be under-reported as the evidence points to some inconsistencies in reporting of sexual initiation by adolescent girls. However, these findings are similar to those reported in other studies conducted in urban slums in Nairobi, and there is no reason to believe that the issue would be more prevalent in certain study arms. ${ }^{28}$ Of the few girls who had initiated sexual intercourse, almost $70 \%$ in Wajir and $80 \%$ in Kibera reported the experience of unwanted sex, indicating high levels of coerced or forced sexual intercourse. Evidence shows that girls who experience sexual violence are also more likely to experience unwanted pregnancy. ${ }^{29,30}$ In the context of urban informal settlements, studies have shown that girls with no safety nets or social support are more vulnerable to coerced sex, compared to girls with more social support. ${ }^{31}$ Results point to the need for increased attention to sexual violence and abuse in resource constrained settings such as in Kibera and Wajir.

The baseline results highlight limited menstrual knowledge among adolescents in both settings, but especially in Wajir. Though a higher proportion of girls (52\% for girls between the ages of 11 and 15 years) in Kibera were able to identify that there was a certain window within the menstrual cycle when conception was possible, less than $15 \%$ could correctly identify the fertile window. In Wajir, less than 10\% had knowledge of this window, and only about 1 in 4 girls aged 13-14 years were able to correctly identify the fertile window (none of the girls aged 11-12 correctly identified this period). Studies in other settings show similar trends. ${ }^{32,} 33$ For example, a study by Lawan and colleagues ${ }^{33}$ showed that though more than half of girls aged 10-19 years in Northern Nigeria knew that conception was possible during a certain window of the menstrual cycle, none could correctly identify the fertile window. This lack of comprehen- 
sive sexual and reproductive health knowledge among young adolescents could possibly be explained by limited open discussion between young people and adults, especially mothers who feel embarrassed to speak to girls about these matters. ${ }^{34}$ Furthermore, though the 2009 National School Health Policy in Kenya ${ }^{35}$ has comprehensive sexuality education as one of the main areas for implementation in schools, only a minority of schools (15\%) offer comprehensive school health programs. ${ }^{36}$ Accurate comprehensive sexuality education results in delayed initiation of sexual activity, increased safe-sex practices, and improved communication in young people's relationships. ${ }^{37}$ Overall, results highlight the need to strengthen sexual and reproductive health education for very young adolescents and to equip them with culturally relevant, accurate, and age-appropriate information about sexuality and relationships. The AGI$K$ health intervention will deliver this information using the Safe Spaces model, which has been shown to have positive effects on young people, including increased sexual and reproductive health knowledge in both rural and urban settings. 7,8

\section{VIOLENCE PREVENTION}

Overall, there was general acceptance of Female Genital Mutilation/Cutting (FGM/C) in Wajir, as the practice is widespread and common in the region. Many young girls in Wajir cited religious approval as the main reason for a positive attitude toward the practice. Young girls in Wajir were also more likely to state that they would have their daughters circumcised in the future. While this project will not have an impact on reducing the prevalence of FGM/C for young girls, the community-level violence-prevention intervention and the Safe Spaces program will focus on changing norms around FGM/C at both community and individual levels, particularly in regard to intentions to circumcise future children.

About one-third of girls in Kibera reported having experienced emotional, physical, and sexual violence. In contrast, fewer than $5 \%$ of girls in Wajir reported experiencing any of these forms of violence. Nonetheless, almost one-third of girls in Wajir reported that they felt scared of being raped and over 1 in 10 said a boy or man had touched them indecently in the past six months. Furthermore, almost $90 \%$ of girls in Kibera and $40 \%$ of girls in Wajir noted that they did not feel safe walking in the community after dark. Studies show that females who were physically or sexually abused face adverse sexual and reproductive health consequences in the long-term. ${ }^{29}$ As suggested by Erulkar and Matheka ${ }^{38}$ in their study on adolescence in Kibera, it is essential to create safety nets for young girls and to address personal security, while also providing social support, as these are key challenges faced by young girls in slums. The AGI-K program will seek to expand safe spaces for girls through the community-level violenceprevention intervention.

The survey measured respondents' attitudes or opinions regarding domestic violence. Equal proportions of young girls in both Kibera and Wajir agreed that a husband is justified in beating a wife for at least one reason, however a higher proportion of girls in Wajir agreed with reasons such as "going out without telling him," "refusing to have sexual intercourse with him," and "burning food." Results suggest ingrained gender norms around the status of women in the communities, which may be influencing girls' attitudes as well as their perceived status (in this case, low status) relative to their male counterparts. The 2008-09 Kenya Demographic and Health Survey showed that 1 in 2 women aged 15-49 years in Kenya also agreed with at least 
one reason that wife beating was justified, 26 which suggests that older women (and mothers) also see the legitimacy of violence that is being transferred to the young girls (daughters). For both Kibera and Wajir, it is imperative to have community-level violence-prevention interventions, especially those that focus on changing community attitudes toward violence against women and girls. Community-level interventions that target change in community attitudes toward gender-based violence will be implemented as part of the AGI-K program.

In conclusion, though the results from the baseline study highlight quite a number of negative issues affecting very young girls in Kibera and Wajir, they also show potential promise in investing in younger adolescent girls. By building girls' assets through a combination of education, social, health, and economic interventions, there is a potential to change their life course. The data that will be generated from AGI-K will help us understand the kinds of interventions that are best positioned to help us achieve this change. 


\section{Appendix A}

\section{AGI-K National External Advisory Committee}

1. Kenya Women Parliamentary Association (KEWOPA)

2. National Gender and Equality Commission

3. Gender Directorate, Ministry of Devolution and Planning

4. Department of Children's Services, Ministry of Labor, Social Security \& Services

5. Department of Policy, Partnership and EAC, Ministry of Education

6. Division of Reproductive Health, Ministry of Health

7. Department of Health, Wajir County

8. County Department/Sector of Education, Wajir County

9. Kadhi, Judicial Service Commission, Wajir County

10. Wajir County Government, Humanitarian Coordinator

11. Kenya Post Office Savings Bank (Postbank)

12. Equity Bank/Equity Group Foundation

13. Gender and Social Development, Kenya Private Sector Alliance

14. Footprints Africa Foundation

15. UNICEF Kenya

16. UN Women

17. UNFPA, Reproductive Health and Youth

18. UNESCO

19. ALDEF - Wajir Local NGO

20. WASDA - Wajir Local NGO

21. Center for Rights Education and Awareness (CREAW)

22. Girl Child Network

23. Center for the Study of Adolescence (CSA)

24. Association Of Media Women in Kenya

25. Department of Community Health, University of Nairobi

\section{AGI-K Kibera External Advisory Committee}

1. Office of the MP, Kibra Constituency

2. Nairobi County Assembly

3. Department of Children's Services, District Children's Officer

4. Deputy Gender Officer - Kibera, Langata Subcounty

5. County Education Officer, Nairobi County

6. District Education Officer, Langata Subcounty

7. Public Health Officer, Langata Subcounty

8. District Health Officer, Langata Subcounty

9. Assistant District Health Officer, Langata Subcounty

10. District Commissioner, National Administration

11. Equity Bank, Kibera Branch

12. Post Bank, Kenyatta Market Branch

13. Kenya Primary School Heads Association - Langata Constituency

14. Kibera Paralegal Network

15. Carolina for Kibera 
16. Undugu Society

17. Shining Hope for Communities Lea Toto

18. Kibera Informal Settlements Association

19. SAVO Foundation CBO

20. Global Communities

21. Umande Trust

22. Concern Worldwide

23. DARAJA

24. African Network for the Prevention and Protection against Child Abuse and Neglect

25. Centre for Rights Education and Awareness

\section{AGI-K Wajir External Advisory Committee}

1. Department of Children's Services, Wajir County

2. Wajir County Government, Humanitarian Coordinator

3. County Director of Education, Wajir County

4. County Health Director, Wajir County

5. County Reproductive Health Coordinator, Wajir County

6. National Drought Management Authority, Hunger Safety Net Program, Secretariat

7. Gender and Social Services, Wajir County

8. Chairman, Court User Committee, Judicial Service Commission, Wajir County

9. Teachers Service Commission, County Director

10. Community Strategy Focal Point, Wajir County, Ministry of Health

11. County Executive Committee Member - Education, Wajir County

12. Equity Bank - Wajir Branch

13. Kenya Primary School Heads Association - Wajir

14. Kadhi, Judicial Service Commission, Wajir County

15. Council of Imam Preachers of Kenya

16. Supreme Council of Kenya Muslims

17. Wajir Paralegal Network

18. Discovery Learning Alliance

19. OXFAM

20. Islamic Relief

21. WASDA

22. ALDEF

23. Mercy Corps

24. Human Rights Watch 


\section{References}

1. Austrian K, Ghati D. Girl centered program design: A toolkit to develop, strengthen \& expand adolescent girls programs: Population Council; 2010.

2. Bruce J, Sebstad J. Building assets for safe and productive lives: A report on a workshop on adolescent girls' livelihoods. Paper presented at Adolescent Girls Livelihoods Meeting; 2004.

3. Robertson L, Mushati P, Eaton JW, et al. Effects of unconditional and conditional cash transfers on child health and development in Zimbabwe: A cluster-randomised trial. The Lancet; 2013;381(9874):1283-1292.

4. Baird SJ, Garfein RS, McIntosh CT, Ozler B. Effect of a cash transfer programme for schooling on prevalence of HIV and herpes simplex type 2 in Malawi: A cluster randomised trial. The Lancet; Apr 7, 2012;379(9823):1320-1329.

5. Fentiman A, Squires M. Save the Children Cash Transfer for Education Pilot in Kenya: Endline Qualitative \& Quantitative Report. Save the Children; 2015

6. Baird S, Ferreira FH, Özler B, Woolcock M. Relative effectiveness of conditional and unconditional cash transfers for schooling outcomes in developing countries: A systematic review. Campbell Systematic Reviews; 2013;9(8).

7. Erulkar A, Muthengi E. Evaluation of Berhane Hewan: A program to delay child marriage in rural Ethiopia. International Family Planning Perspectives; 2009;35(1):6-14.

8. $\quad$ Austrian K, Muthengi E. Safe and Smart Savings Products for Vulnerable Adolescent Girls in Kenya and Uganda: Evaluation Report. Nairobi: Population Council; 2013.

9. Tavrow P, Muthengi-Karei E, Obbuyi A, Omollo V. Community norms about youth condom use in Western Kenya: Is transition occurring? African Journal of Reprodive Health. Jun 2012;16(2):241-252.

10. Campbell C, MacPhail C. Peer education, gender and the development of critical consciousness: Participatory HIV prevention by South African youth. Social Science \& Medicine. 2002;55(2):331-345.

11. Miller M, Reichelstein J, Salas C, Zia B. Can you help someone become financially capable? A meta-analysis of the literature. The World Bank Research Observer. 2015:Ikv009.

12. Fernandes D, Lynch Jr JG, Netemeyer RG. Financial literacy, financial education, and downstream financial behaviors. Management Science 2014;60(8):1861-1883.

13. Austrian K, Muthengi E. Can economic assets increase girls' risk of sexual harassment? Evaluation results from a social, health and economic asset-building intervention for vulnerable adolescent girls in Uganda. Children and Youth Services Review. 2014;47:168-175.

14. Amin S, Rahman L, Ainul S, Rob U, Zaman B, Akter R. Enhancing Adolescent Financial Capabilities through Financial Education in Bangladesh. Population Council. 2010;72010.

15. African Population and Health Research Center. Nairobi Cross Sectional Slum Survey (NCSS) II: Report on Demographic Behavior, Health Outcomes and Livelihoods Conditions of the Urban Poor in Nairobi Informal Settlements [Unpublished Report]. Nairobi: African Population and Health Research Center; 2014.

16. Handa S, Peterman A, Huang C, Halpern C, Pettifor A, Thirumurthy H. Impact of the Kenya Cash Transfer for Orphans and Vulnerable Children on early pregnancy and marriage of adolescent girls. Social Science \& Medicine. 2015.

17. Beguy D, Mumah J, Gottschalk L. Unintended pregnancies among young women living in urban slums: Evidence from a prospective study in Nairobi city, Kenya. PLoS One. 2014;9(7): e101034.

18. Ermisch J, Pronzato C. Causal effects of parents' education on children's education: ISER Working Paper Series; 2010.

19. Currie J, Goodman J. Parental socioeconomic status, child health, and human capital. International Encyclopedia of Education. 2010;3:253-259.

20. Witt SD. Parental influence on children's socialization to gender roles. Adolescence. 1997;32(126):253-259. 
21. African Population and Health Research Center. Population and health dynamics in Nairobi's informal settlements: Report of the Nairobi Cross-sectional Slums Survey (NCSS) 2000. Nairobi: African Population and Health Research Center; 2002.

22. Rutstein SO, Johnson K, MEASURE OM. The DHS wealth index: ORC Macro, MEASURE DHS; 2004.

23. Merttens F, Hurrell A, Marzi M, et al. Kenya Hunger Safety Net Programme Monitoring and Evaluation Component. 2013.

24. Lloyd CB. Education for Girls: Alternative Pathways to Girls' Empowerment. Paper commissioned by Girl Hub, a strategic partnership between Nike Foundation and the UK Department for International Development. 2013.

25. Kenya U. Are our children learning? Annual learning assessment report, 2011: Uwezo Kenya Nairobi; 2012.

26. Kenya National Bureau of Statistics (KNBS). Kenya Demographic and Health Survey 2008-09. Calverton, Maryland: KNBS and ICF Macro; 2010.

27. Ngware M, Abuya B, Admassu K, Mutisya M, Musyoka P, Oketch M. Quality and Access to Education in Urban Informal Settlements in Kenya. Nairobi, Kenya: African Population and Health Research Center; 2013.

28. Soler-Hampejsek E, Grant MJ, Mensch BS, Hewett PC, Rankin J. The effect of school status and academic skills on the reporting of premarital sexual behavior: Evidence from a longitudinal study in rural Malawi. Journal of Adolescent Health. 2013;53(2):228-234.

29. Miller E, Levenson R, Herrera L, Kurek L, Stofflet M, Marin L. Exposure to partner, family, and community violence: Gang-affiliated Latina women and risk of unintended pregnancy. Journal of Urban Health. Feb 2012;89(1):74-86.

30. Mumah J, Kabiru CW, Izugbara C, Mukiira C. Coping with unintended pregnancies: Narratives from adolescents in Nairobi's slums. STEP UP Research Report Nairobi: Kenya: African Population and Health Research Center; 2014.

31. Erulkar A, Ferede A. Social exclusion and early or unwanted sexual initiation among poor urban females in Ethiopia. International Perspectives on Sexual \& Reproductive Health. 2009;35(4).

32. Orringer K, Gahagan S. Adolescent girls define menstruation: A multiethnic exploratory study. Health care for women international. 2010;31(9):831-847.

33. Lawan U, Nafisa WY, Musa AB. Menstruation and menstrual hygiene amongst adolescent school girls in Kano, Northwestern Nigeria: Original research article. African Journal of Reproductive Health. 2010;14(3):201-207.

34. Crichton J, Ibisomi L, Gyimah So. Mother-daughter communication about sexual maturation, abstinence and unintended pregnancy: Experiences from an informal settlement in Nairobi, Kenya. Journal of Adolescence. 2012;35(1):21-30.

35. Republic of Kenya. National School Health Policy. Ministry of Public Health and Sanitation and Ministry of Education; 2009.

36. Republic of Kenya. Accelerating Attainment of Health Goals: The first Kenya Health Sector Strategic and Investment Plan - KHSSP July 2012 - June 2018. Nairobi, Kenya: Ministry of Medical Services and Ministry of Public Health \& Sanitation; 2012.

37. Silva M. The effectiveness of school-based sex education programs in the promotion of abstinent behavior: A meta-analysis. Health Education Research. 2002;17(4):471-481.

38. Erulkar A, Matheka JK. Adolescence in the Kibera slums of Nairobi, Kenya. Nairobi and New York: Population Council; 2007. 

In partnership with: 